\title{
Influence of Compressibility Effect on Supersonic Combustion Modeling
}

\author{
Liu Chen ${ }^{1}$ Wei $\mathrm{Yao}^{2}$ and XueJun Fan ${ }^{3}$ \\ Key Laboratory of High-Temperature Gas Dynamics, Institute of Mechanics, CAS, Beijing 100190, China \\ School of Engineering Science, University of Chinese Academy of Sciences, Beijing 100049, China
}

\begin{abstract}
Large eddy simulation is applied to study the compressibility effect on supersonic combustion modeling, through adding compressibility corrections into the original model, including reaction rate correction (RRC), and subgrid stress correction (SSC). Two correction results and the result without compressibility effect correction (WCEC) are compared with the experimental results, including the fields of velocity, composition, and temperature and the lift-off height of flame. The results show that the effect of two compressibility correction models on the lift-off height of flame can be ignored, whereas the width of time-averaged velocity field, the peak value of the composition field, and the reaction zone length of time-averaged temperature can be affected by the two compressibility correction models. And the more obvious differences can be foud in the instantaneous fields of velocity and tempetature. A probe is located at $(X / D=32.3, Y / D=0, Z / D=1.1)$ to measure the instantaneous temperature of three cases (WCEC, RRC, SSC). The results reveal that the combustion field has a periodic characteristic, and the SSC has an effect on it.
\end{abstract}

\section{Nomenclature}

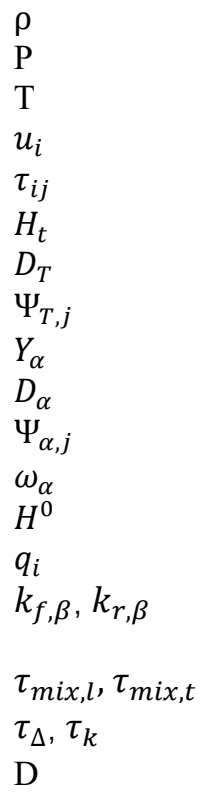

Superscripts

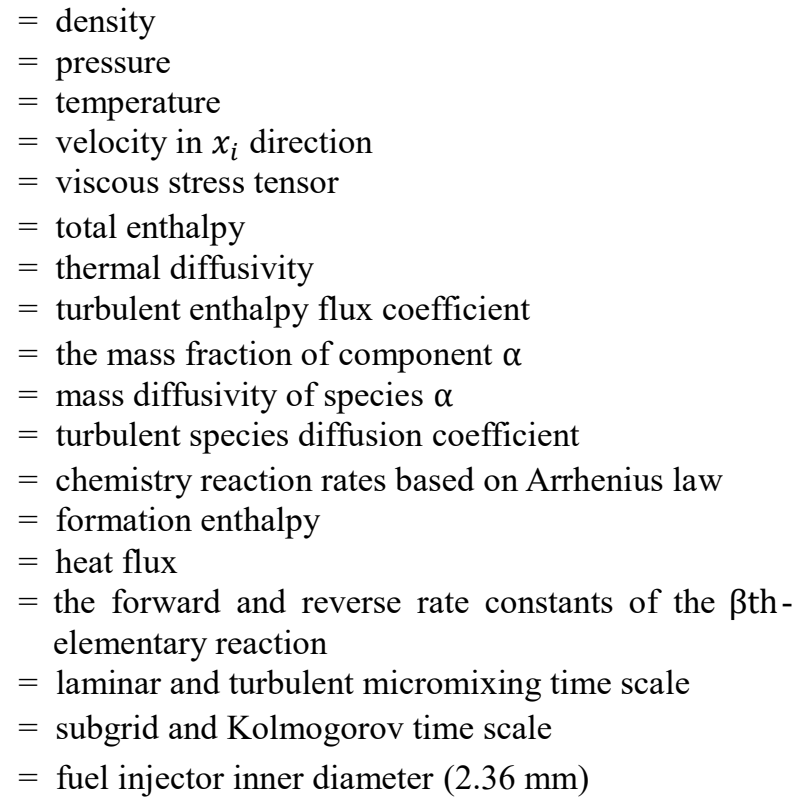

$=$ Favre-averaged quantity

\footnotetext{
${ }^{1}$ Master student, Institute of Mechanics (CAS), chenliu1@imech.ac.cn.

${ }^{2}$ Associate Professor, Institute of Mechanics (CAS), weiyao@imech.ac.cn, AIAA member (Corresponding author).

${ }^{3}$ Professor, Institute of Mechanics (CAS), xfan@imech.ac.cn, AIAA lifetime member
}

American Institute of Aeronautics and Astronautics 
$=$ averaged quantity

Subscripts

$i, j$

$=$ direction indices

$\alpha$

$=$ species index

\section{Introduction}

Scramjet (supersonic combustion ramjet) engines are the potential propulsion system for high-speed transport of missiles and aircraft. In a scramjet, high-speed air is compressed by the ram effect in the inlet to be the supersonic airstream, which then mixed with the fuel (typically hydrogen or hydrocarbons) for ignition and burning. The thrust is obtained by the ejection of high enthalpy gases through a nozzle. The critical problem is how to finalize combustion as completely as possible within the short residence time of the order of magnitude of $1 \mathrm{~ms}$. To design an efficient scramjet combustor, a better understanding of the combustion process is significant. Scramjet experiments are tremendously difficult for the current level of science and technology: the prohibitive economic cost of flight testing, the intricacy in reproducing realistic flight conditions in ground facilities, the technical difficulties in measuring reacting flow quantities at supersonic speeds, as well as the complexity of the involved aerothermodynamics and combustion kinetics, all making Computational Fluid Dynamics (CFD) not the complementary, but the necessary analysis and design tool for high-speed propulsion systems [1]. In this regard, highfidelity modeling can become a fundamental tool to design and optimize scramjet combustors, through improving the mixing, flame anchoring, and combustion efficiency.

For the modeling of mixing and combustion at small scales in supersonic reacting flows, all effects of compressibility must be considered to better reproduce the experimental results [2]. Theoretical analysis shows that the mixing and combustion at high Mach numbers are driven not only by the vortex stretching induced by kinetic energy transfer, as in subsonic reacting flows but also by the compressibility and the baroclinic effects. Shan [3] has proposed two compressibility corrections to the flamelet/progress variable model for the supersonic combustion modeling through accounting for compressibility-induced variations in pressure and temperature in the source term. A correction to the law of mass action is proposed and applied to model dissociating nitrogen and oxygen, in order to account for the compressibility effect [4].

In this paper, the influence of compressibility on the reaction rates and the subgrid stress is examined. Compressibility favors combustion by increasing the reaction rate, whose underlying physics is that supersonic combustion occurs locally at a constant volume roughly [5], thus the pressure will increase during the reaction progress. Corrections were proposed to account for the influence of compressibility on the reaction rate by Ingenito et al [2]. In addition, the interaction of turbulence and shock is essential in supersonic combustion. Under strong compression, both of the dynamic viscosity coeffect and bulk viscosity coeffect are important for subgrid stress, thus a correction of the two coeffects has been proposed by Cook and Cabot [1].

\section{Numerical Models}

\section{A. Governing Equations}

The governing equations mainly include conservation equations and transport equation, which are represented by a set of conservative variables $\bar{\rho}, \tilde{u}_{i}, \widetilde{H}_{t}, \tilde{Y}_{\alpha}$,

$$
\begin{gathered}
\frac{\partial \bar{\rho}}{\partial t}+\frac{\partial \bar{\rho} \tilde{u}_{j}}{\partial x_{j}}=0 \\
\frac{\partial \bar{\rho} \tilde{u}_{i}}{\partial t}+\frac{\partial \bar{\rho} \tilde{u}_{i} \tilde{u}_{j}}{\partial x_{j}}+\frac{\partial \bar{p}}{\partial x_{i}}-\frac{\partial \tilde{\tau}_{i j}}{\partial x_{j}}=-\frac{\partial \tau_{i j}}{\partial x_{j}} \\
\frac{\partial \bar{\rho} \widetilde{H}_{t}}{\partial t}+\frac{\partial \bar{\rho} \tilde{u}_{j} H_{t}}{\partial x_{j}}+\frac{\partial}{\partial x_{j}}\left(\bar{\rho} D_{T} \frac{\partial \widetilde{H}_{t}}{\partial x_{j}}\right)-\frac{\partial \bar{p}}{\partial t}-\frac{\partial \tilde{u}_{j} \tilde{\tau}_{i j}}{\partial x_{j}}=-\frac{\partial \Psi_{T, j}}{\partial x_{j}}
\end{gathered}
$$

American Institute of Aeronautics and Astronautics 


$$
\begin{gathered}
\frac{\partial \bar{\rho} \tilde{Y}_{\alpha}}{\partial t}+\frac{\partial \bar{\rho} \tilde{u}_{j} \tilde{Y}_{\alpha}}{\partial x_{j}}+\frac{\partial}{\partial x_{j}}\left(\bar{\rho} D_{\alpha} \frac{\partial \tilde{Y}_{\alpha}}{\partial x_{j}}\right)=-\frac{\partial \Psi_{\alpha, j}}{\partial x_{j}}+\bar{\omega}_{\alpha} \\
\bar{p}=\bar{\rho} R \tilde{T} \\
\widetilde{H}_{t}=\widetilde{H}^{0}+\int_{0}^{T} C_{P} d T+\frac{1}{2} \tilde{u}_{i} \tilde{u}_{i}
\end{gathered}
$$

Here the bar (-) and the tilde ( ) symbolize averaged and Faver-averaged quantities, respectively, $t$ represents the time, $x_{i}$ denotes the Cartesian coordinate in the direction $i$. In addition, $\bar{\rho}, \bar{p}$ and $\tilde{T}$ represent density, pressure and temperature, respectively, and $\tilde{\tau}_{i j}$ is the viscous stress tensor, $\widetilde{H}_{t}=\widetilde{H}+0.5 \tilde{u}_{i}^{2}$ is the total absolute enthalpy obtained from the absolute enthalpy $\widetilde{H}$ and the resolved kinetic energy, $\widetilde{H}^{0}$ is the formation enthalpy. Heat flux vector, mass fraction and averaged mass production rate are denoted by $q_{i}, \widetilde{Y}_{\alpha}$ and $\widetilde{\omega}_{\alpha}$, respectively. $D_{\alpha}$ is mixture-averaged mass diffusivity of species $\alpha$, and $D_{T}$ represents the thermal diffusivity. $R=R_{u} / W$ is the gas constant, where $R_{u}$ is the universal gas constant, and $W$ is the molar weight of corresponding composition.

The computable averaged momentum diffusive flux is given by

$$
\tilde{\tau}_{i j}=\bar{\rho} v(\tilde{T})\left(2 \tilde{S}_{i j}-\frac{2}{3} \delta_{i j} \tilde{S}_{k k}\right)
$$

Which depends on the computable strain-rate tensor of the resolved scales

$$
\tilde{S}_{i j}=\frac{1}{2}\left(\frac{\partial \tilde{u}_{i}}{\partial x_{j}}+\frac{\partial \tilde{u}_{j}}{\partial x_{i}}\right)
$$

The fluxes $\left(\Psi_{T, j}\right.$ and $\left.\Psi_{a, j}\right)$ require specific modeling for the unclosed equations. The turbulent enthalpy flux term $\Psi_{T, j}=\bar{\rho}\left(\widetilde{u_{j} H_{t}}-\widetilde{u}_{j} \widetilde{H}_{t}\right)$ is modeled by the gradient diffusion assumption:

$$
\Psi_{T, j}=-2 \bar{\rho} \frac{v_{t}}{P r_{t}} \frac{\partial \widetilde{H}_{t}}{\partial x_{j}}
$$

Like the modeling of turbulent enthalpy flux term $\Psi_{T, j}$, the turbulent species diffusion term $\Psi_{a, j}=\widetilde{u}_{j} \widetilde{Y}_{a}-\tilde{u}_{j} \widetilde{Y}_{a}$ is also modeled, using gradient diffusion assumption:

$$
\Psi_{a, j}=-2 \bar{\rho} \frac{v_{t}}{S c_{t}} \frac{\partial \tilde{Y}_{a}}{\partial x_{j}}
$$

\section{B. Turbulence Model}

The traditional subgrid stress tensor can be modeled with the Boussinesq hypothesis, calculated by subgrid scale turbulent viscosity $\mu_{t}$ and rate-of strain tensor $\tilde{S}_{i j}$. However, this model may be failed at high Mach number, because of the presentence of shocks. In the regions containing shocks, the dilatation $\nabla \cdot \tilde{V}$ is large, which will significantly change the local $\tilde{\tau}_{i j}$. Based on this, a correction model has been proposed by Cabot and Cook [1], considering the effect of dilation and bulk viscosity. The use of the bulk viscosity term is the key to capture shocks without destroying vorticity, as $\beta_{k}$ can be made large (to smooth shocks) without harming small-scale turbulence in regions, where $\nabla$. $\tilde{V} \approx 0$.

A grid-dependence component is applied to both of dynamic coeffect and viscosity coeffect. It means that $\mu=$ $\mu_{f}+\mu_{\Delta}$ and $\beta=\beta_{f}+\beta_{\Delta}$, where the $f$ subscript denotes physical viscosity and the $\Delta$ subscript denotes artificial viscosity [6]. The spectral-like models for $\mu_{\Delta}$ and $\beta_{\Delta}$ are

$$
\begin{gathered}
\mu_{\Delta}=C_{\mu}^{r} \eta^{r} \\
\beta_{\Delta}=C_{\beta}^{r} \eta^{r} \\
\eta^{r}=\rho \Delta^{(r+2)} \frac{\left|\Delta^{r} S\right|}{\mathrm{r}}=2,4,6 \ldots
\end{gathered}
$$

American Institute of Aeronautics and Astronautics 
Here, $\Delta$ and $\mathrm{S}=(\mathbf{S}: \mathbf{S})^{1 / 2}$ represent local grid spacing and the magnitude of the strain rate tensor, respectively. The $\nabla^{r} S$ term denotes a successive application of the Laplacian operator, and we let $\mathrm{r}=4$, corresponding to the biharmonic operator in this paper. And the symbol (-) denotes the operator of truncated-Gaussian filter.

\section{Turbulent Combustion Model}

The turbulence-chemistry interaction is accounted for by the partially stirred reactor (PaSR) model [7]. In PaSR, the final reaction rate averaged reaction rate $\bar{\omega}_{\alpha}$ is determined by the characteristic time scale of chemistry $\left(\tau_{c}\right)$ and micro-mixing $\left(\tau_{\text {mix }}\right)$,

$$
\bar{\omega}_{\alpha}=\frac{\tau_{c}}{\tau_{c}+\tau_{\operatorname{mix}}} \omega_{\alpha}
$$

where $\omega_{\alpha}$ is the reaction rate over the current integration time step calculated from the Arrhenius law.

$$
\omega_{\alpha}=\sum_{\beta=1}^{M} \omega_{\alpha, \beta}=\sum_{\beta=1}^{M} W_{\alpha}\left(v_{\alpha, \beta}^{\prime \prime}-v_{\alpha, \beta}^{\prime}\right)\left(k_{f, \beta} \prod_{\alpha=1}^{L}\left[c_{\alpha}\right]^{v_{\alpha, \beta}^{\prime}}-k_{r, \beta} \prod_{\alpha=1}^{L}\left[c_{\alpha}\right]^{v_{\alpha, \beta}^{\prime \prime}}\right)
$$

Here, $v_{\alpha, \beta}^{\prime \prime}$ and $k_{f, \beta}$ denote the forward stoichiometric coefficient and forward rate constant of $\beta$ th-elementary reaction, whereas $v_{\alpha, \beta}^{\prime}$ and $k_{f, \beta}$ are their reverse counterparts, and $L$ and $M$ are the total numbers of species and elementary reactions, respectively. The reaction rates constants obey the Arrhenius law, and $c_{\alpha}$ is the molar concentration of species $\alpha$.

The micro-mixing time scale is approximately equal to the turbulent mixing time scale $\left(\tau_{\text {mix,t }}\right)$, which is determined by the geometric mean of Kolmogorov time scale $\left(\tau_{k}\right)$ and the SGS time scale $\left(\tau_{\Delta}\right)$.

Based on the theory of Ingenito et. al [8], there is an effect of local Mach number on reaction rates that is negative where the flow expands and positive where flow compresses. The correctional reaction rate is

$$
\bar{\omega}_{c}=\left(1 \pm 2 M a_{s}^{2}\right) \bar{\omega}_{\alpha}=\frac{\left(1 \pm 2 M a_{s}^{2}\right) \tau_{c}}{\tau_{c}+\tau_{m i x}} \omega_{\alpha}
$$

where $M a_{s}$ is subgrid Mach number. The above correction on the reaction rates $\bar{\omega}_{\alpha}$ accounting for the compressibility effect is implemented in the modeling to examine its effect on the combustion fields.

\section{Test Facility}

This experiment is performed by cheng et al [9], about a supersonic lifted co-flowing hydrogen-air diffusion flame. Ultraviolet spontaneous vibrational Raman scattering and laser-induced predissociative fluorescence from a $\mathrm{KrF}$ excimer laser are combined to simultaneously measure temperature and composition concentration. The experimental parameters are given in Table 1.

American Institute of Aeronautics and Astronautics 


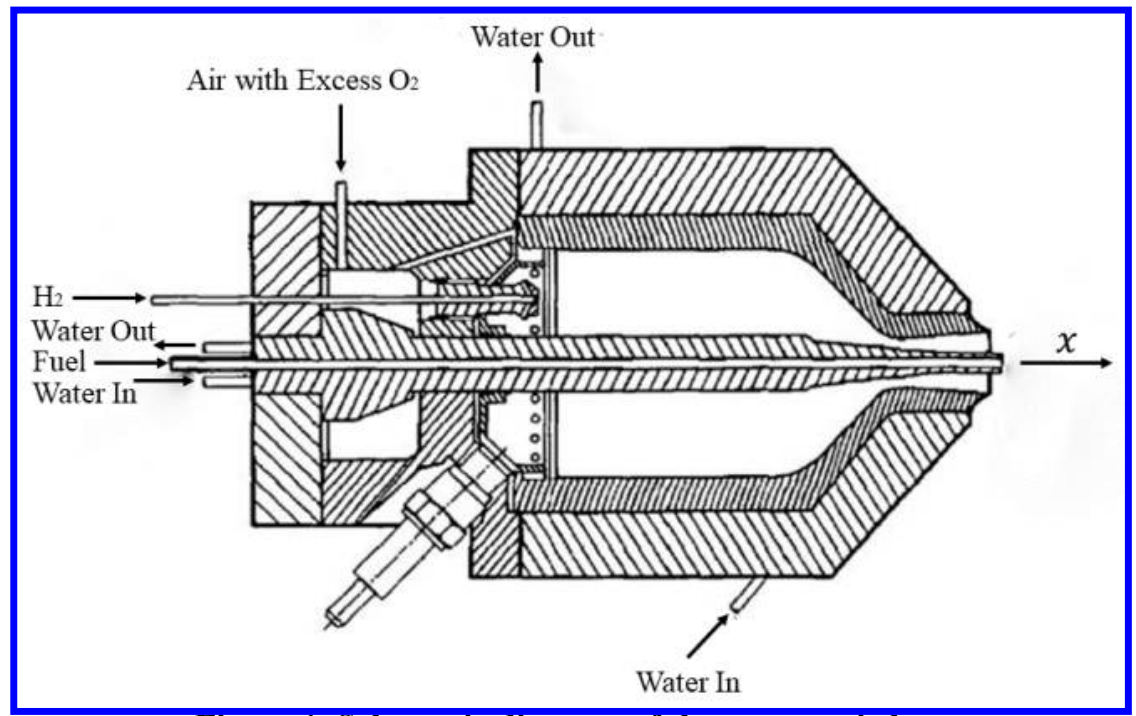

Figure 1. Schematic diagram of the supersonic burner.

Table. 1. Geometrical parameters (mm)

\begin{tabular}{rc}
\hline Nozzle exit i.d. & 17.78 \\
Fuel injector i.d. & 2.36 \\
Fuel injector o.d. & 3.81 \\
\hline \hline
\end{tabular}

\section{E. Flow Channel and Mesh}

The mesh is generated by a Cartesian grid method, which can generate high orthogonality hexahedral grid. $96.1 \%$ cells have a skewness less than 0.032 , and $97 \%$ of them have an orthogonal quality higher than 0.97 . The specific geometry and grid are shown in Figure 2 and 3.
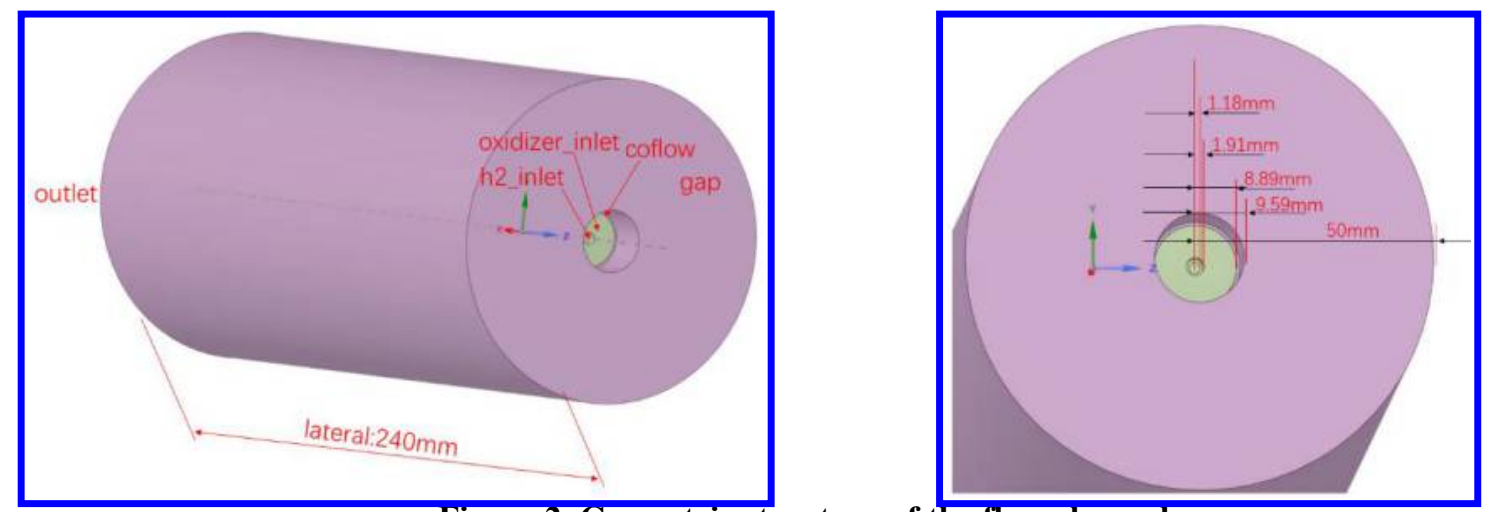

Figure 2. Geometric structure of the flow channel 


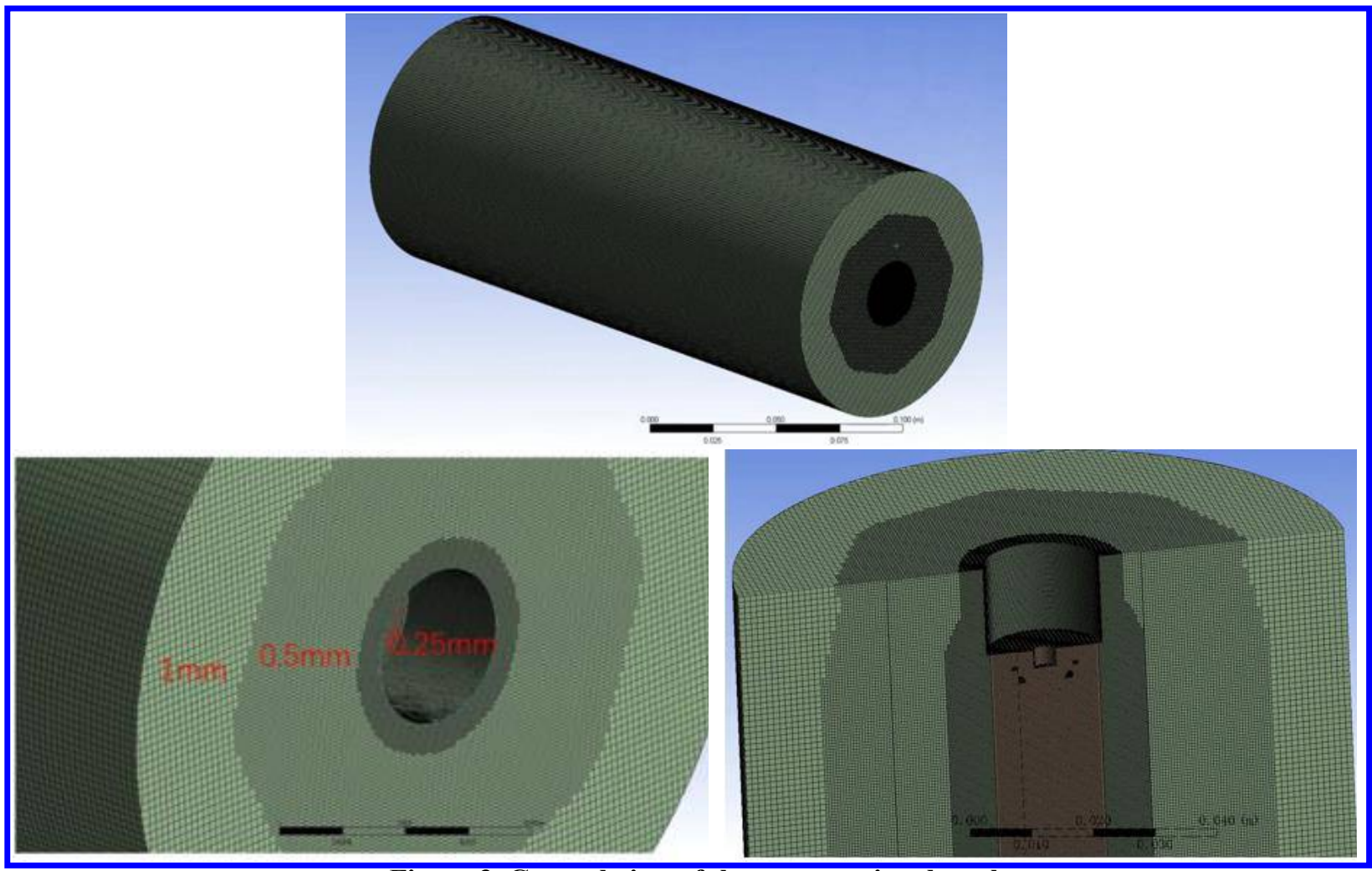

Figure 3. General view of the computational mesh

\section{F. Solver and Computational Setup}

This combustion process is solved by the compressible reacting flow solver AstroFoam, which is based on the compressible flow solver rhoCentralFoam, distributed by the open-source CFD package OpenFoam [10]. The major progress in this research include 1) JANAF thermophysical properties and multicomponent diffusivities calculated by the CHEMKIN- II package [11]; 2) in situ adaptive tabulation (ISAT) method to accelerate the costly stiff chemistry solving; 3) absolute/sensible enthalpy equation is solved for transient reacting flows instead of the sensible internal energy equation; 4) dynamic load balancing technique to redistribute the computational load among processors.

Both of AstroFoam and rhoCentralFoam solver were first validated with various frozen flows, including the canonical shock tube problem, forward step flow, hypersonic flow over a biconic, and supersonic jets [12-19]. The solver was then applied for various scramjet combustor cases [20-25] to examine its accuracy and robustness in the engineering modeling of supersonic combustion.

In this paper, three cases are tested, including WCEC, RRC and SSC. The abbreviations of WCEC, RRC and SSC mean word group of without compressibility effect correction, reaction rate correction and subgrid stress correction. The specific boundary conditions and corresponding types in AstroFoam are listed in Table 2 and 3.

Table 2. Supersonic burner operation conditions.

\begin{tabular}{cccc}
\hline \hline & Fuel & Vitiated air & External air \\
\hline \hline $\mathrm{P}(\mathrm{Pa})$ & - & 107,000 & 101325 \\
$\mathrm{~T}(\mathrm{~K})$ & 595 & 1250 & 300 \\
$\mathrm{U}(\mathrm{m} / \mathrm{s})$ & 1780 & 1420 & 0 \\
$Y_{\mathrm{O}_{2}}$ & - & 0.245 & 0.233 \\
$Y_{\mathrm{N}_{2}}$ & - & 0.580 & 0.767 \\
$Y_{\mathrm{H}_{2} \mathrm{O}}$ & - & 0.175 & - \\
$Y_{\mathrm{H}_{2}}$ & 1 & - & - \\
\hline
\end{tabular}


Table 3. The specific types of boundary conditions in AstroFoam

\begin{tabular}{ccccc}
\hline \hline & Inlet & Outlet & Farfield & Wall \\
\hline \hline $\mathrm{P}$ & FixedValue & zeroGradie & fixedVakue(101325) & zeroGradient \\
$\mathrm{T}$ & fixedValue(static temperature) & inletOutlet & inletOutlet & zeroGradient \\
$\mathrm{U}$ & fixedValue & inletOutlet & PressureInletOutletVelocity & slip \\
Compositions & fixedValue & inletOutlet & (lateral) & zeroGradient \\
\hline \hline
\end{tabular}

A reaction mechanism with 11 species and 23 reactions is applied to this simulation, as listed in Table 4 .

\begin{tabular}{cccc}
\hline \hline & Table 4. 11-species 23-reactions chemical scheme & \\
\hline \hline Reaction & $\mathrm{A}$ & $\mathrm{B}$ & $E_{a}$ \\
$\mathrm{H} 2+\mathrm{O} 2=2 \mathrm{OH}$ & $0.170 \mathrm{E}+14$ & 0.00 & 47780 \\
$\mathrm{OH}+\mathrm{H} 2=\mathrm{H} 2 \mathrm{O}+\mathrm{H}$ & $0.117 \mathrm{E}+10$ & 1.30 & 3626 \\
$\mathrm{O}+\mathrm{OH}=\mathrm{O} 2+\mathrm{H}$ & $0.400 \mathrm{E}+15$ & -0.50 & 0 \\
$\mathrm{O}+\mathrm{H} 2=\mathrm{OH}+\mathrm{H}$ & $0.506 \mathrm{E}+05$ & 2.67 & 6290 \\
$\mathrm{H}+\mathrm{O} 2+\mathrm{M}=\mathrm{HO} 2+\mathrm{M}$ & $0.361 \mathrm{E}+18$ & -0.72 & 0 \\
$\mathrm{OH}+\mathrm{HO} 2=\mathrm{H} 2 \mathrm{O}+\mathrm{O} 2$ & $0.750 \mathrm{E}+13$ & 0.00 & 0 \\
$\mathrm{H}+\mathrm{HO} 2=2 \mathrm{OH}$ & $0.140 \mathrm{E}+15$ & 0.00 & 1073 \\
$\mathrm{O}+\mathrm{HO} 2=\mathrm{O} 2+\mathrm{OH}$ & $0.140 \mathrm{E}+14$ & 0.00 & 1073 \\
$2 \mathrm{OH}=\mathrm{O}+\mathrm{H} 2 \mathrm{O}$ & $0.600 \mathrm{E}+09$ & 1.30 & 0 \\
$\mathrm{H}+\mathrm{H}+\mathrm{M}=\mathrm{H} 2+\mathrm{M}$ & $0.100 \mathrm{E}+19$ & -1.00 & 0 \\
$\mathrm{H}+\mathrm{H}+\mathrm{H} 2=\mathrm{H} 2+\mathrm{H} 2$ & $0.920 \mathrm{E}+17$ & -0.60 & 0 \\
$\mathrm{H}+\mathrm{H}+\mathrm{H} 2 \mathrm{O}=\mathrm{H} 2+\mathrm{H} 2 \mathrm{O}$ & $0.600 \mathrm{E}+20$ & -1.25 & 0 \\
$\mathrm{H}+\mathrm{OH}+\mathrm{M}=\mathrm{H} 2 \mathrm{O}+\mathrm{M}$ & $0.160 \mathrm{E}+23$ & -2.00 & 0 \\
$\mathrm{H}+\mathrm{O}+\mathrm{M}=\mathrm{OH}+\mathrm{M}$ & $0.620 \mathrm{E}+17$ & -0.60 & 0 \\
$\mathrm{O}+\mathrm{O}+\mathrm{M}=\mathrm{O} 2+\mathrm{M}$ & $0.189 \mathrm{E}+14$ & 0.00 & 0 \\
$\mathrm{H}+\mathrm{HO} 2=\mathrm{H} 2+\mathrm{O} 2$ & $0.125 \mathrm{E}+14$ & 0.00 & 4788 \\
$\mathrm{HO} 2+\mathrm{HO} 2=\mathrm{H} 2 \mathrm{O} 2+\mathrm{O} 2$ & $0.200 \mathrm{E}+13$ & 0.00 & 3800 \\
$\mathrm{H} 2 \mathrm{O} 2+\mathrm{M}=\mathrm{OH}+\mathrm{OH}+\mathrm{M}$ & $0.130 \mathrm{E}+18$ & 0.00 & 1800 \\
$\mathrm{H} 2 \mathrm{O} 2+\mathrm{H}=\mathrm{HO} 2+\mathrm{H} 2$ & $0.160 \mathrm{E}+13$ & 0.00 & 75800 \\
$\mathrm{H} 2 \mathrm{O} 2+\mathrm{OH}=\mathrm{H} 2 \mathrm{O}+\mathrm{HO} 2$ & $0.100 \mathrm{E}+14$ & 0.00 & 0280 \\
$\mathrm{O}+\mathrm{N} 2=\mathrm{NO}+\mathrm{N}$ & $0.140 \mathrm{E}+15$ & 0.00 & 0 \\
$\mathrm{~N}+\mathrm{O} 2=\mathrm{NO}+\mathrm{O}$ & $0.640 \mathrm{E}+10$ & 1.00 & 0.00 \\
$\mathrm{OH}+\mathrm{N}=\mathrm{NO}+\mathrm{H}$ & $0.400 \mathrm{E}+14$ & & \\
\hline \hline
\end{tabular}

\section{Results and discussion}

\section{A. Grid independence analysis}

Figure 4 shows the nondimensional temperature and velocity predicted by different mesh resolutions. The temperature and velocity profiles are generally similar for the three mesh resolutions. The results based on the meshes with $20 \mathrm{M}$ and $30 \mathrm{M}$ cells agree better except that the peaks are lower for the mesh with $30 \mathrm{M}$ cells. In the following analysis, the mesh of $20 \mathrm{M}$ cells is used to save computational expense. 

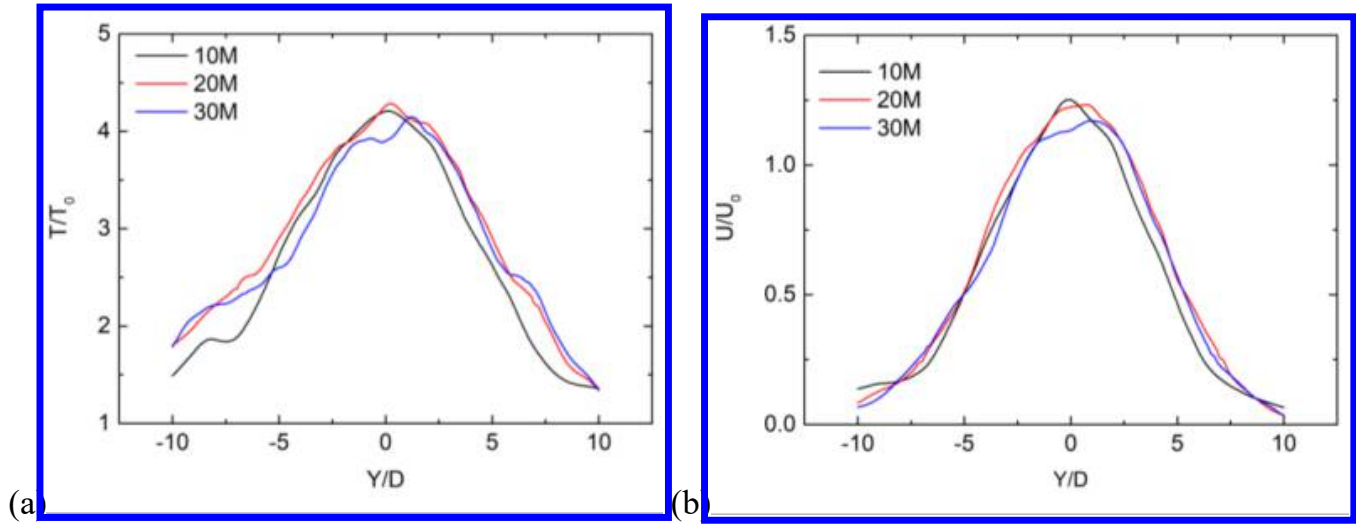

Figure 4. (a) Temperature and (b) velocity predicted by different mesh resolutions

\section{B. Velocity Fields}

In figure 5 , the distributions of velocity fields with three cases are analyzed based on the data obtained from four cross sections $(\mathrm{X} / \mathrm{D}=10.8,21.5,32.3,43.1)$. All three results agree well with the experimental measurements, especially for the downstream locations. At $\mathrm{X} / \mathrm{D}=10.8$, the velocity within the jet width is overpredicted in the three cases. The three predictions are almost identical, with only minor difference at the downstream locations.
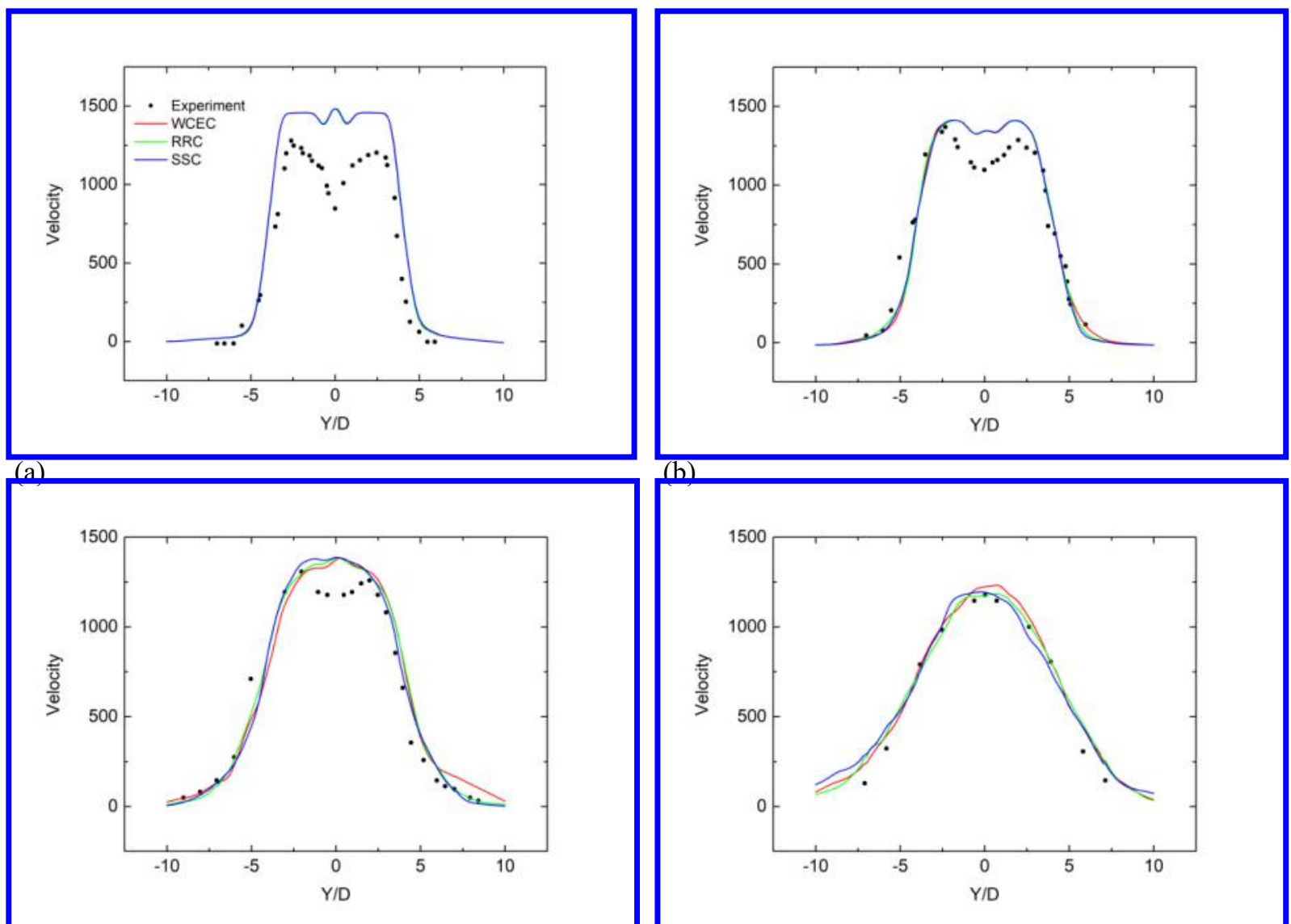

(c)

Figure 5. Velocity profiles at (a) $X / D=10.8$, (b) 21.5, (c) 32.3, and (d) 43.1.

Figure 6 shows the distributions for time-averaged velocity. The velocity contours are similar for the RRC and SSC cases, while larger difference is found for the WCEC case. The velocity field can be divided into two parts, i.e., the mainstream area and the coflow area. The shape of the mainstream is tapering. The coflow area is induced by the

American Institute of Aeronautics and Astronautics 
momentum diffusion of the mainstream, and the width of two cases (WCEC and RRC) is about $0.4 \mathrm{~m}$, whereas the width of the SSC is about $0.6 \mathrm{~m}$, and the $\mathrm{x}$-coordinate of all three cases is beyond 0.22 .

a)
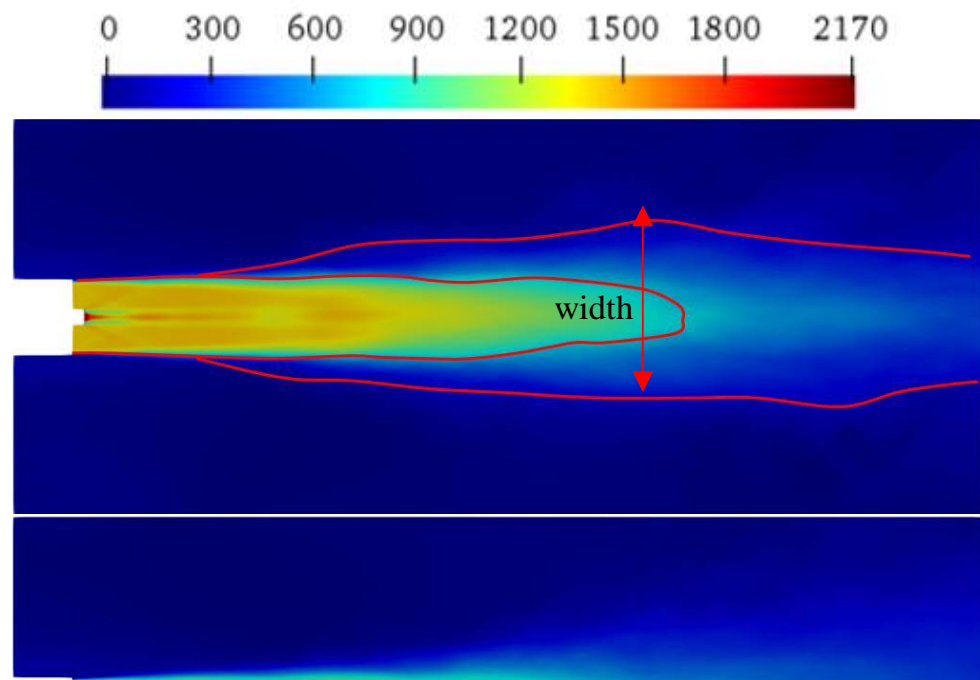

b)

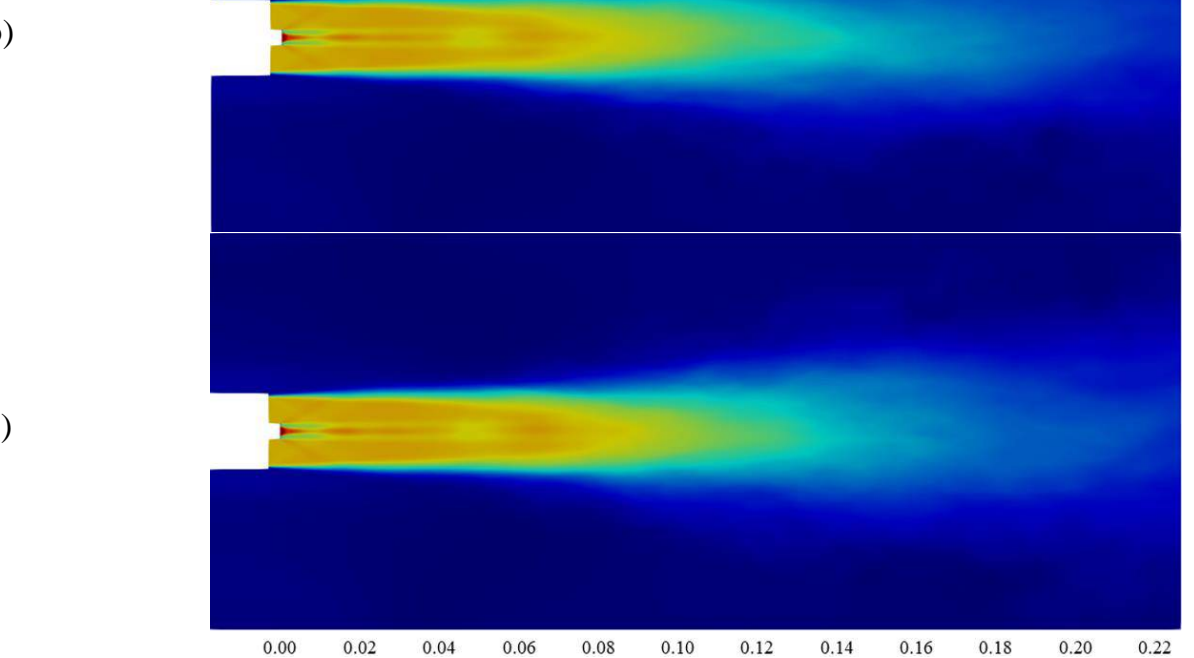

c)

Figure 6. Time-averaged velocity contours predicted by (a)WCEC, (b) RRC and (c) SSC

Figure 7 shows the instantaneous velocity fields. The instantaneous large-scale structure of RRC is almost consistent with the flow structure of WCEC, which implies that the correction of reaction rates has little effects on the instantaneous velocity structure. However, there are some differences between the WCEC and SSC cases, because the bulk viscosity has been considered in the SSC model, which can influence the subgrid stress at high Mach numbers.

However, through comparing the velocity contours of mark position $\mathrm{Ci}(\mathrm{i}=1,2$ and 3 ) with $\mathrm{Ai}$ and $\mathrm{Bi}$, it is found that the development and broken velocity of flow field of SSC is faster than the other two cases, because the SSC model provides correct rate of subgrid-scale energy transfer [6], and the flow field can make transition to turbulence easily.

Through observing the large-scale structure of flow fields, the development process of velocity fields can be divided into three parts, including establishment, instability, and establishment. In the first process, two strands of jets approximately keep the velocity profile, until reaching point A. Due to the sheer stress effect, the oxygen jet is surrounded by a low-velocity area. And in the second process, the front of jets begins to narrow down with shear effects enhancing, and eventually lose stability, as illustrated in Figure 7 (c). In the last process, flow fields begin to rebuild, stable jets form gradually at flow direction until reaching the instability point A. And then, the flow field will experience next instability process. In other words, there is a kind of periodicity in the flow fields. 

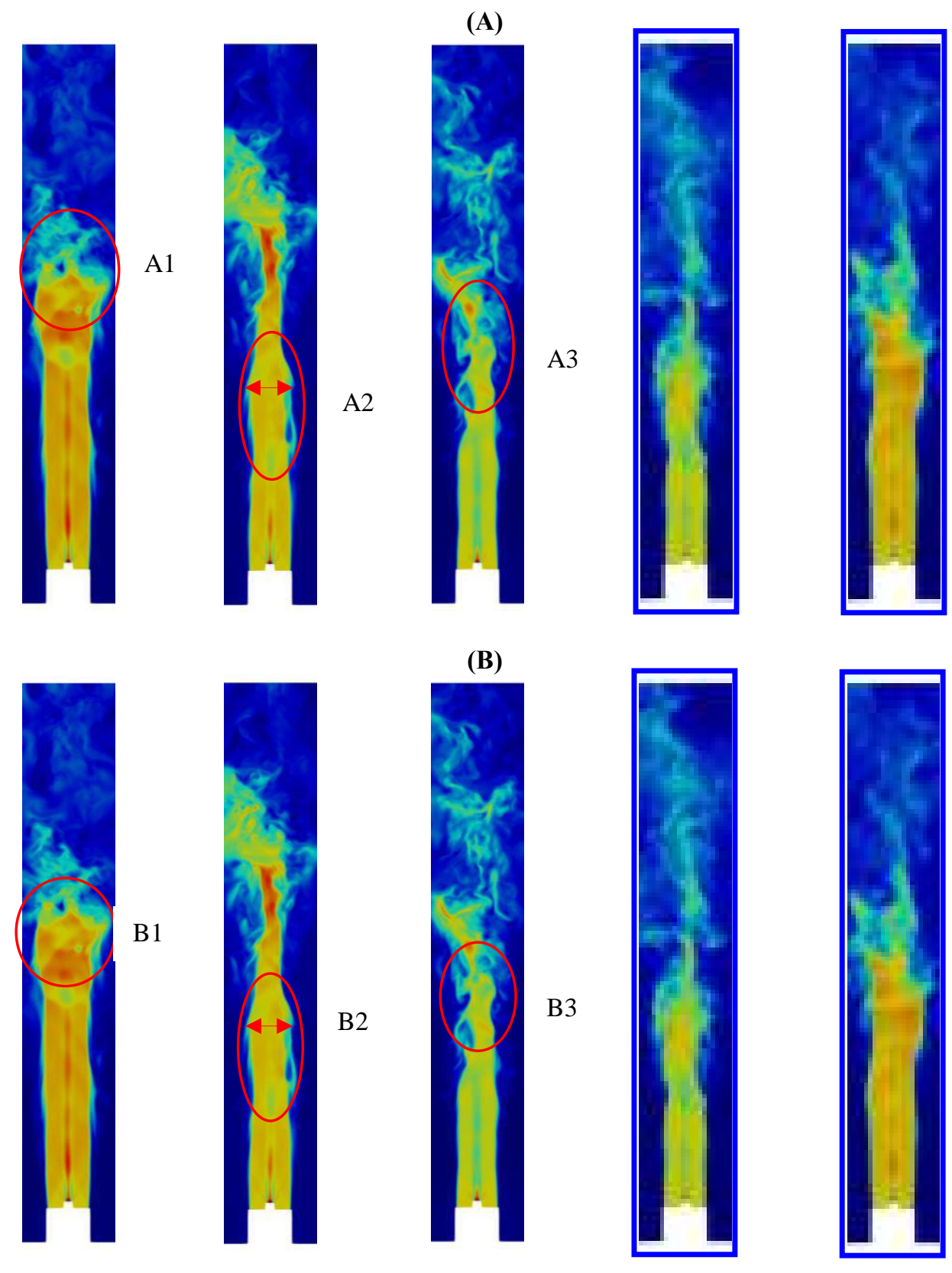
(C)

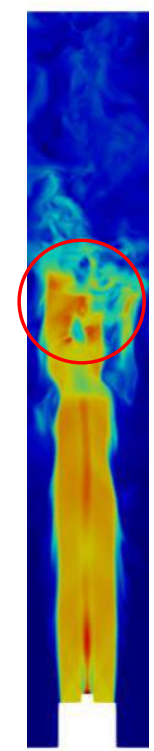

$\mathrm{C} 1$

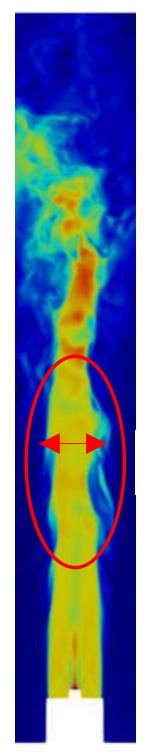

$\mathrm{C} 2$

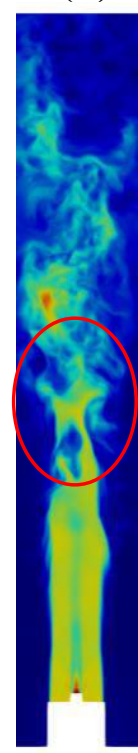

C3
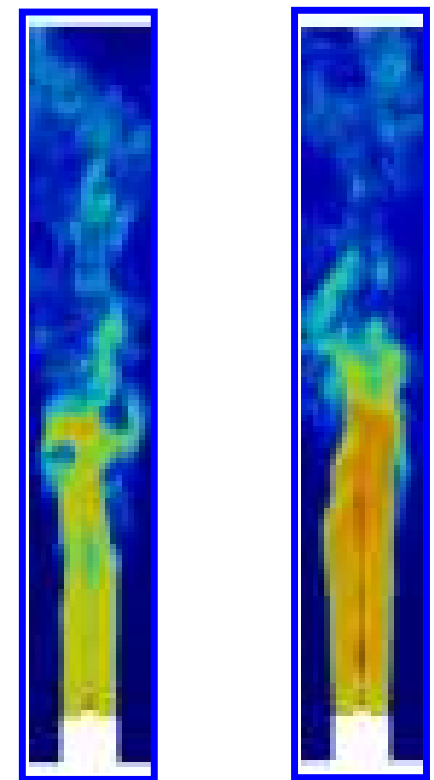

Figure 7. Instantaneous velocity fields of three cases, A-C)WCEC, RRC, SSC, at $t=t_{0}+$ $3 \Delta t, t_{0}+7 \Delta t, t_{0}+11 \Delta t, t_{0}+15 \Delta t, t_{0}+19 \Delta t$, where $t_{0}$ is a steady combustion time, and $\Delta t$ is $2 \times 10^{-5} \mathrm{~s}$.

\section{Composition Fields}

The influence of the compressibility corrections on the prediction of species distribution is analyzed for $\mathrm{H}_{2} \mathrm{O}, \mathrm{H}_{2}$, and $\mathrm{O}_{2}$ at four cross sections.

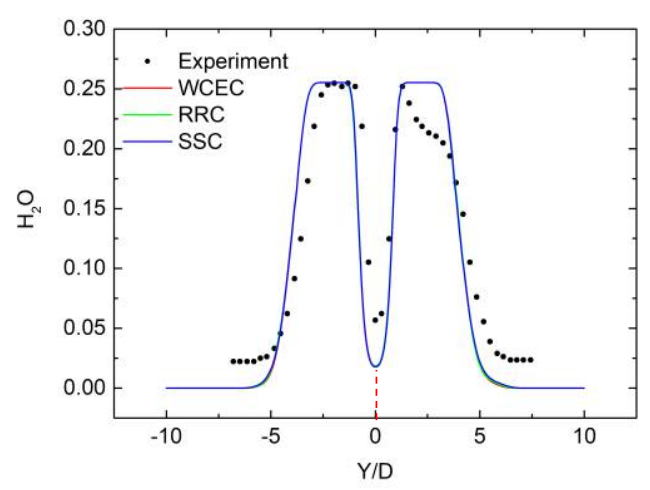

(a)

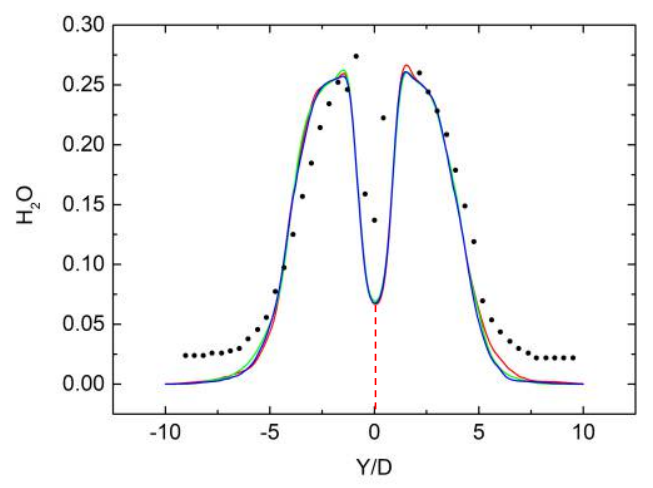

(b) 


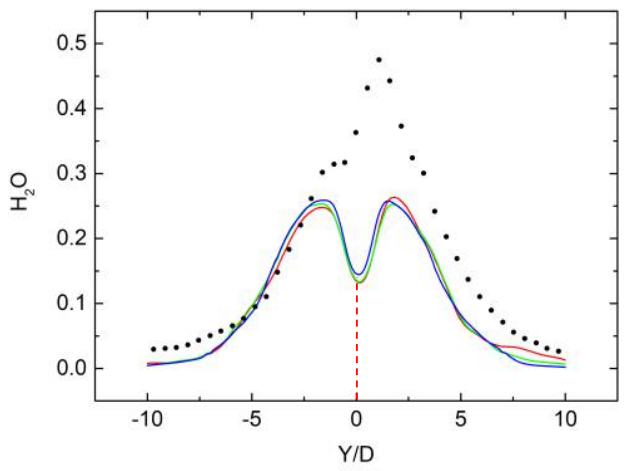

(c)

Figure 8. The mean mass fraction distribution of $\mathrm{H}_{2} \mathrm{O}$ at four cross sections, a-d) $\mathrm{X} / \mathrm{D}=10.8,21.5,32.3$, 43.1.

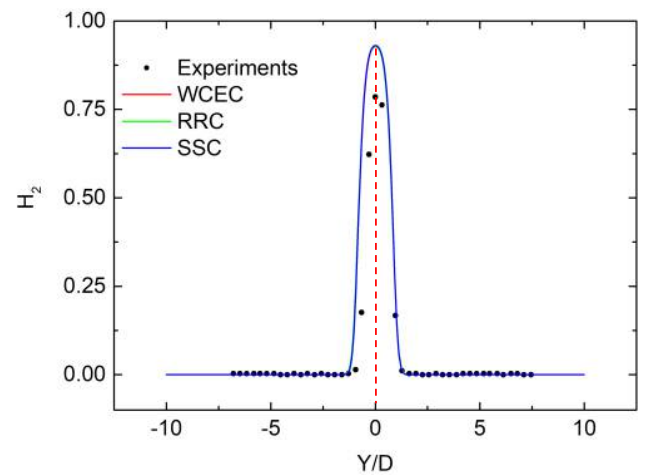

(a)

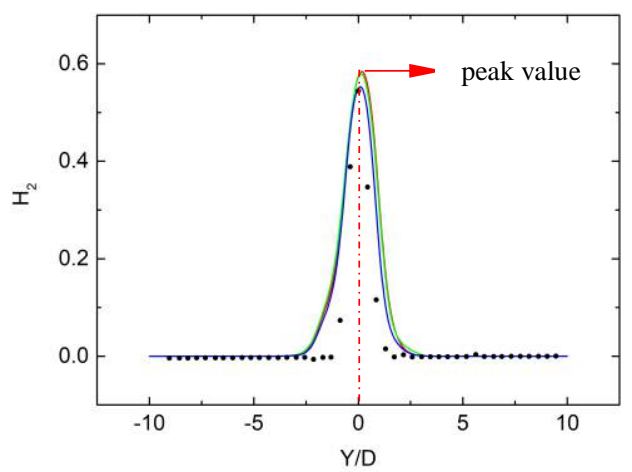

(c)

Figure 9. The mean mass fraction distribution of $\mathrm{H}_{2}$ at four cross sections, a-d) $\mathrm{X} / \mathrm{D}=10.8,21.5,32.3,43.1$.

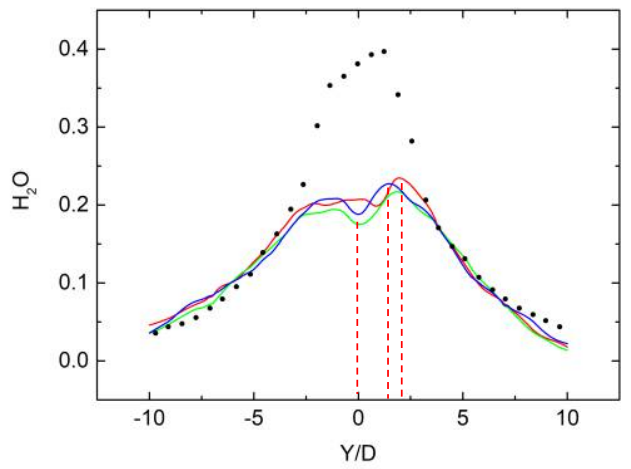

(d)

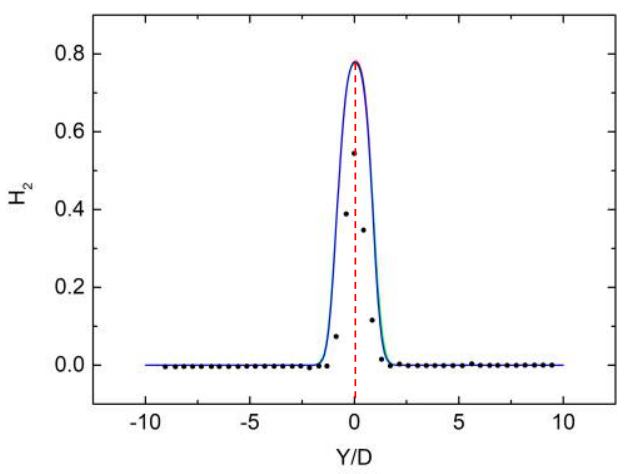

(b)

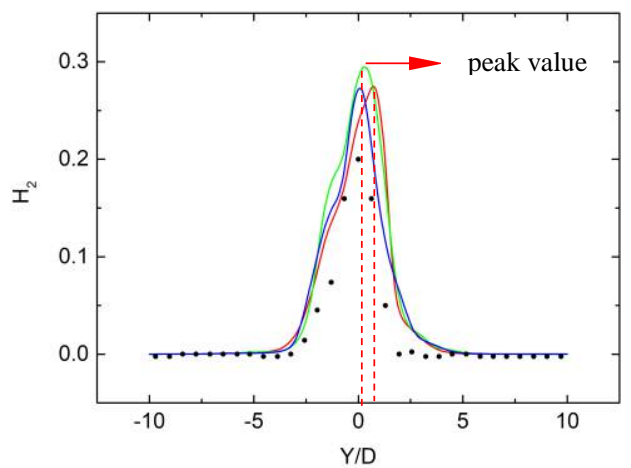

(d) 


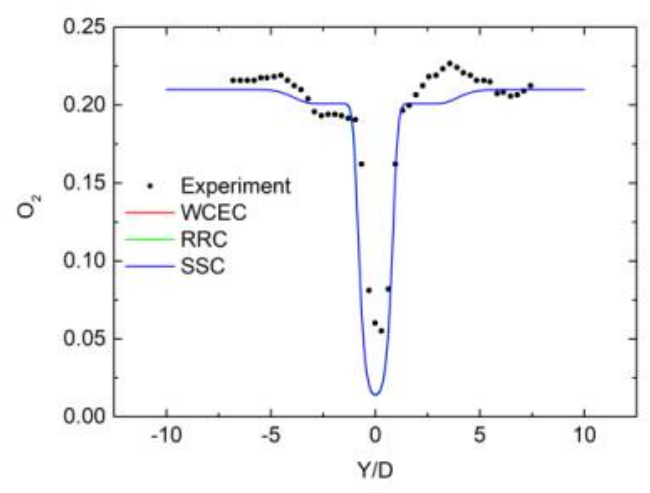

(a)

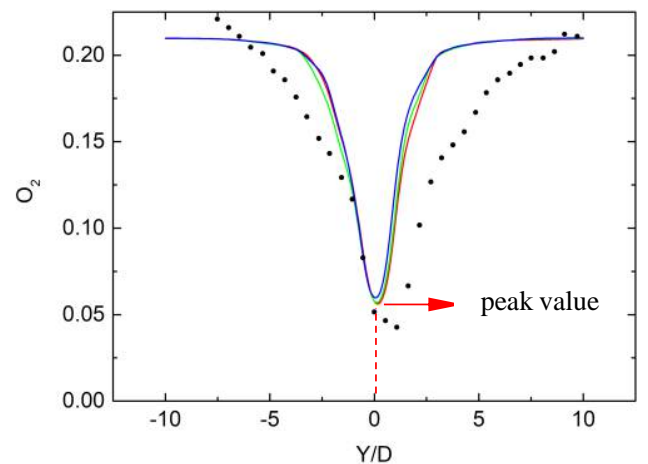

(c)

(d)
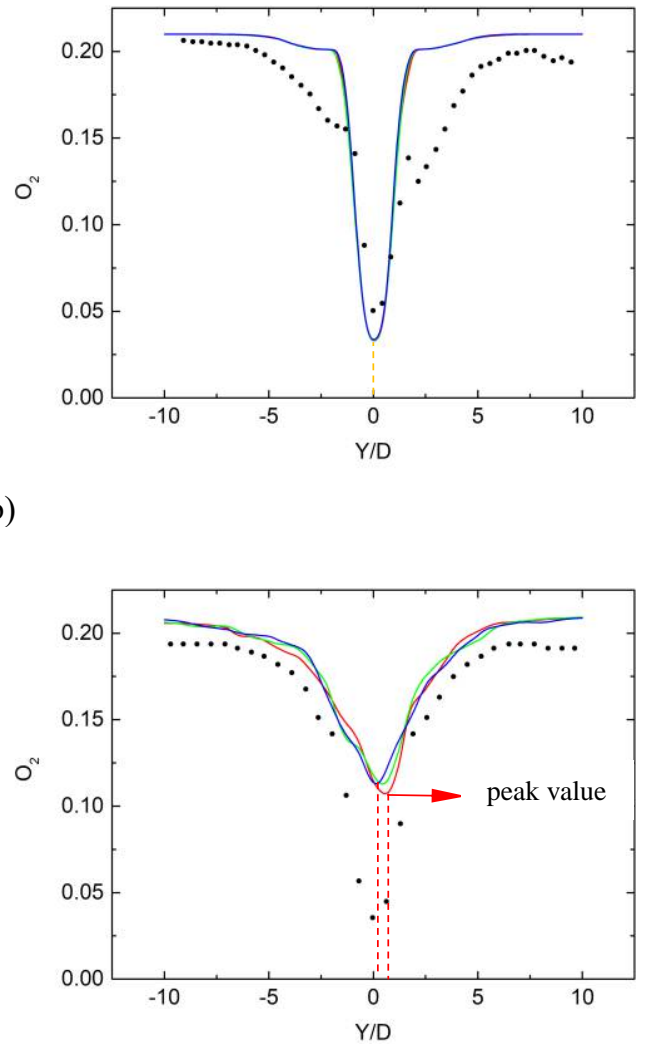

(b)

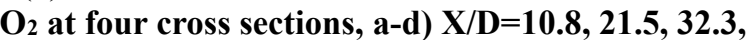
43.1.

Through qualitative observe Figure 8-10,1) the results of three cases are basically consistent, but there still are some tiny differences, 2) compared with experiment, the downstream results of three cases are underpredicted, 3) the symmetry of SSC is relatively well. These tiny differences are reflected in the downstream position, i.e. X/D=32.3, 43.1. At $\mathrm{X} / \mathrm{D}=43.1$ of Figure 8, the mass fraction of $\mathrm{H}_{2} \mathrm{O}$ of $\mathrm{RRC}$ is least in the centric position, meaning the weak reaction rates, and this phenomenon also can be revealed by the higher mass fraction of $\mathrm{H}_{2}$ and $\mathrm{O}_{2}$. It seems that the effect on reaction rates of RRC at the compression area is negative, having a conflict with the theory of Ingenito. In fact, the real reason is the asymmetry of the combustion field, which will cause the uneven distribution at the circumference, validated by the bias axis of symmetry of Figure 8-10. Thus, a proper method of data analysis is needed to consider the asymmetry effect at the circumference. Averaging at the circumference direction is a considerable approach. The large deviation between three cases and experiment at the downstream position is an interesting problem. The most probable reason is the flow characteristic of coaxial jet combustion.

Observing the position of symmetry of three cases, the coordinate of SSC is basically close to the origin point 0 , which reveal the statistic uniformity of composition field, at circumferences direction. The reason is that the hyperviscosity model provides the correct rate of subgrid-scale energy transfer, which can promote the diffusion of subgrid-scale vortices in each direction.

\section{Temperature Fields}

Figure 11 shows the prediction of temperature at four cross sections. The results of the three cases are almost identical, instead of the centric reacting zone. Both of RRC and SSC can affect the combustion field, resulting in the different reaction process, and the peak temperature. RRC case can change the reaction rates, through the subgrid Mach number, thus the accelerated and moderative chemical reaction can change the temperature field, obviously, especially in the reaction zone. As for SSC case, this model also can change the combustion field, through affecting the mixing zone, because SSC can promote the velocity field transform to turbulence, as shown in Figure 7. In Figure 12 , we can obviously the difference of centric reacting zone, where the reacting length is different, marked by a white

American Institute of Aeronautics and Astronautics 
ellipse. The reacting length of WCEC is longer than the other two cases, meaning that RRC and SSC model indeed can promote the combustion process, in supersonic jet combustion.

Through observing the overall structure of Figure 12, we can know that temperature field can be into three parts, i.e., reacting zone, mainstream zone, and diffusion zone. Reacting zone refers to the region where the fuel $\mathrm{H}_{2}$ and the oxidizer $\mathrm{O}_{2}$ mixed and reacted to drastically increase the temperature. Mainstream zone refers to the region where the temperature is roughly consistent with the oxidizer stream. In the diffusion zone, the temperature decreases gradually.

Compared with the experimental data, all the three cases well predict the temperature profiles at $\mathrm{X} / \mathrm{D}=10.8,21.5$. However, the peak values are all underpredicted at $\mathrm{X} / \mathrm{D}=32.3,43.1$.

The underpredicting temperature can reveal a hidden law of coaxial supersonic jet combustion, referring to the periodicity. It means that the process of mixing, autoignition, combustion, and quenching is cyclical Therefore, the instantaneous temperature field will be studied, validating the existence of periodic small scale structure.

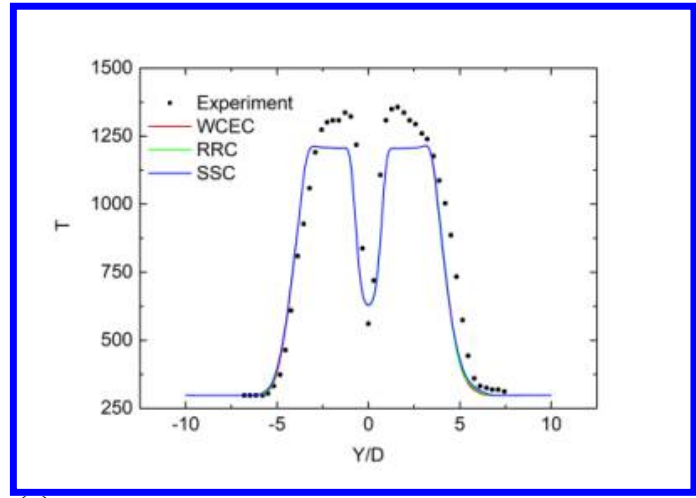

(a)

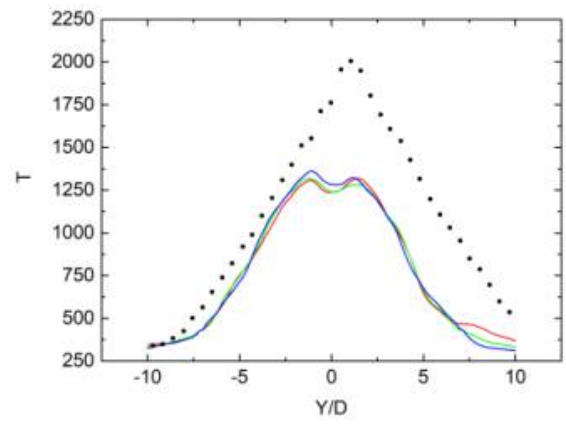

(c)

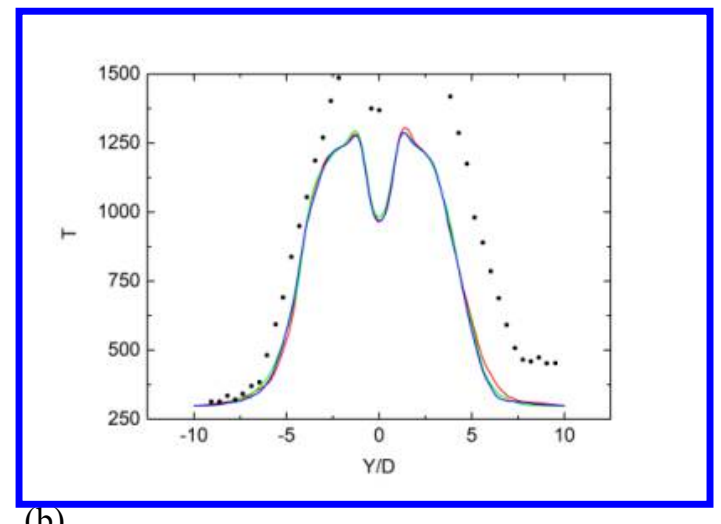

(b)

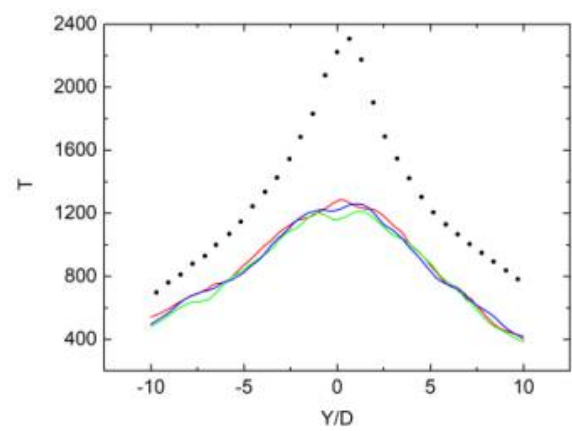

(d)

Figure 11. The mean temperature distribution at four cross sections, a-d) $X / D=10.8,21.5,32.3$, 43.1. 
a)
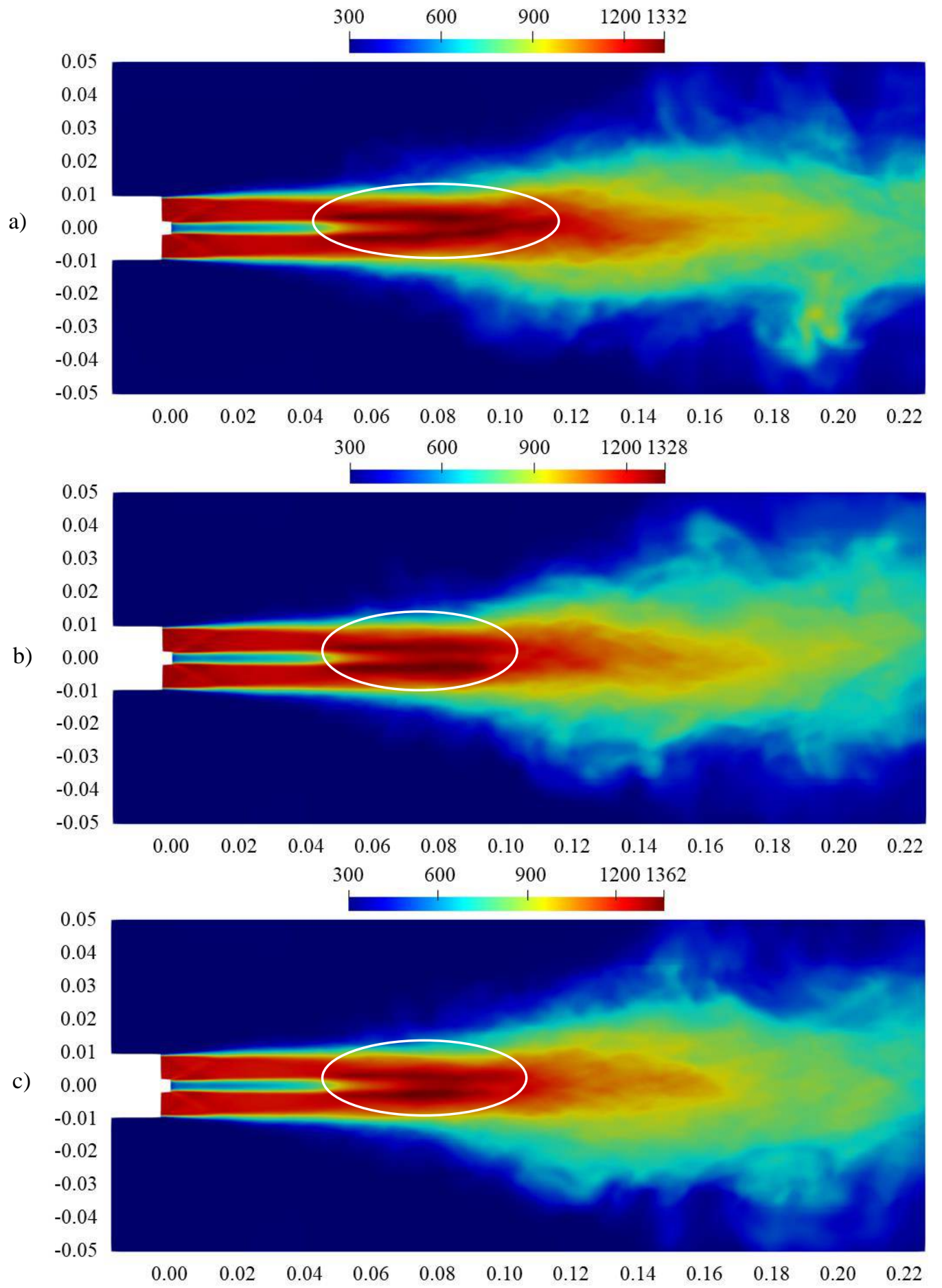

Figure 12. The cloud diagrams of mean temperature of three cases, a-c) WCEC, RRC, SSC.

The instantaneous temperature fields in Figure 13 exhibit a periodicity characteristic. The combustion process can be described as the following five steps, 1) two strands of jets propagate forward steadily; 2) when jets reach a particular zone (called mixing zone) circumjacent oxidizer jets begin to approach central hydrogen jets, and combustion begins to happen, along with mixing process; 3 ) the flame seems to propagate upstream, and the reason is that the large scale vortexes occur far from inlet, so these large vortexes can disturb the upstream flows, 4) the forward flame quenches, instead of the tail of jet flame, which will be pushed forward by the latter upstream flows; 5) the jets propagate forward again, following the above four steps.

American Institute of Aeronautics and Astronautics 
Now, the periodic characteristic can be applied to explain the underpredicted temperature, when the averaging time is inappropriate. In Figure 13, the instantaneous field represents a whole jet flame periodicity, and the red line represents the position $\mathrm{X} / \mathrm{D}=32.3$. Through observing the combustion process, we can know that the measurement of periodicity in supersonic coaxial jet flame actually includes the flame and the unburnt gases. Through counting the number of burnt gases at $\mathrm{X} / \mathrm{D}=32.3$, we can know that a half of the combustion process is burnt gases, and the other half of the process approximately is the unburnt gases, where the temperature is lower than $700 \mathrm{~K}$. Therefore, the simulation temperature of three cases is underpredicted at $\mathrm{X} / \mathrm{D}=32.3$ when the averaging time is 3 FTT, as shown in Figure 14, because the averaging time actually contains the unburnt process, whereas the temperature of Figure (b) can catch the peak value in the reacting zone, because the averaging time is appropriate $1 / 3$ of the periodicity, which can avoid the unburnt process.

In other words, the averaging time is significant when we deal with the supersonic coaxial supersonic jet combustion. It is necessary to know the specific experimental measurement methods, such as the measurement time and the sensitivity of the sensors, in order to choose a suitable averaging time.
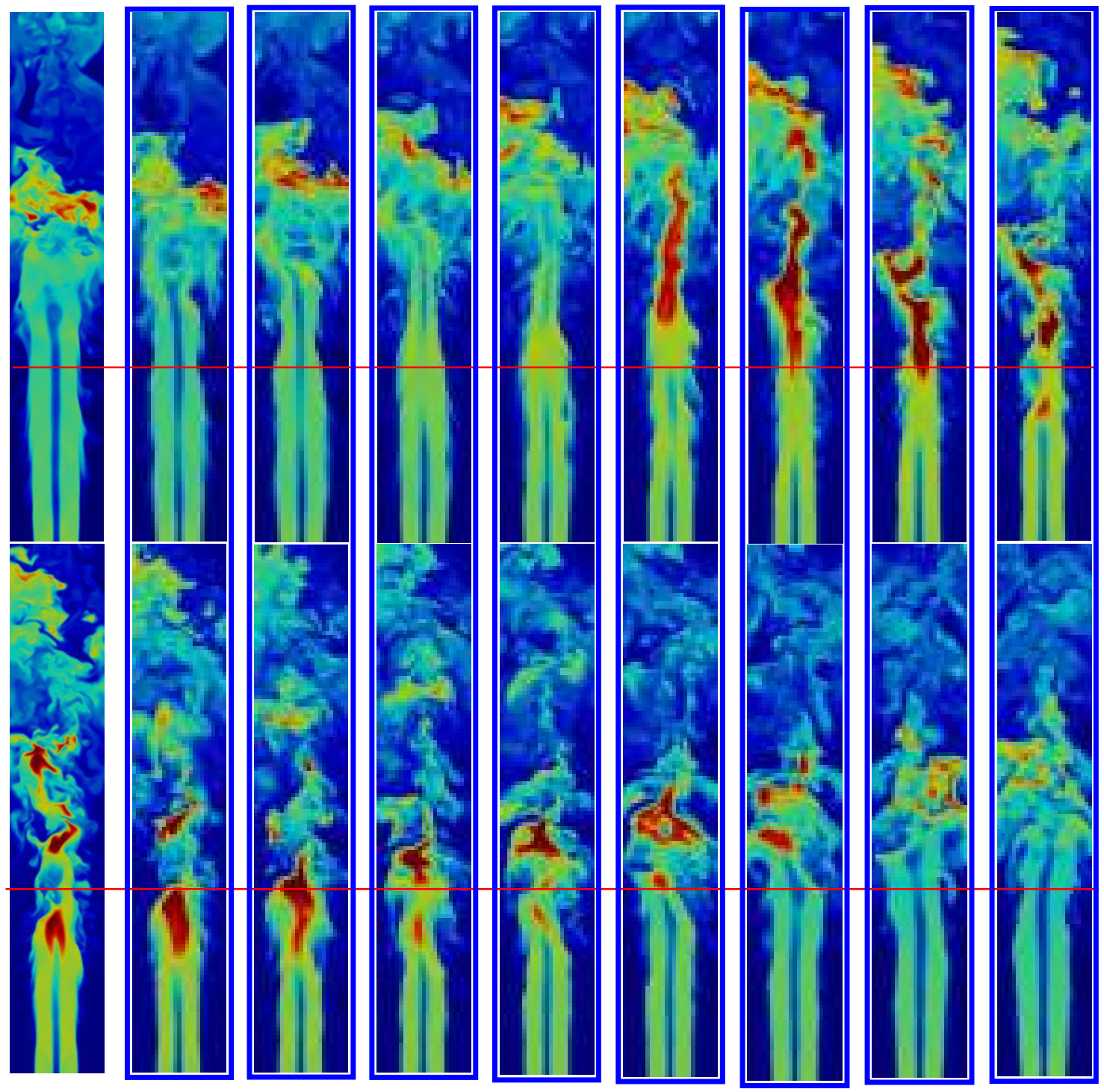


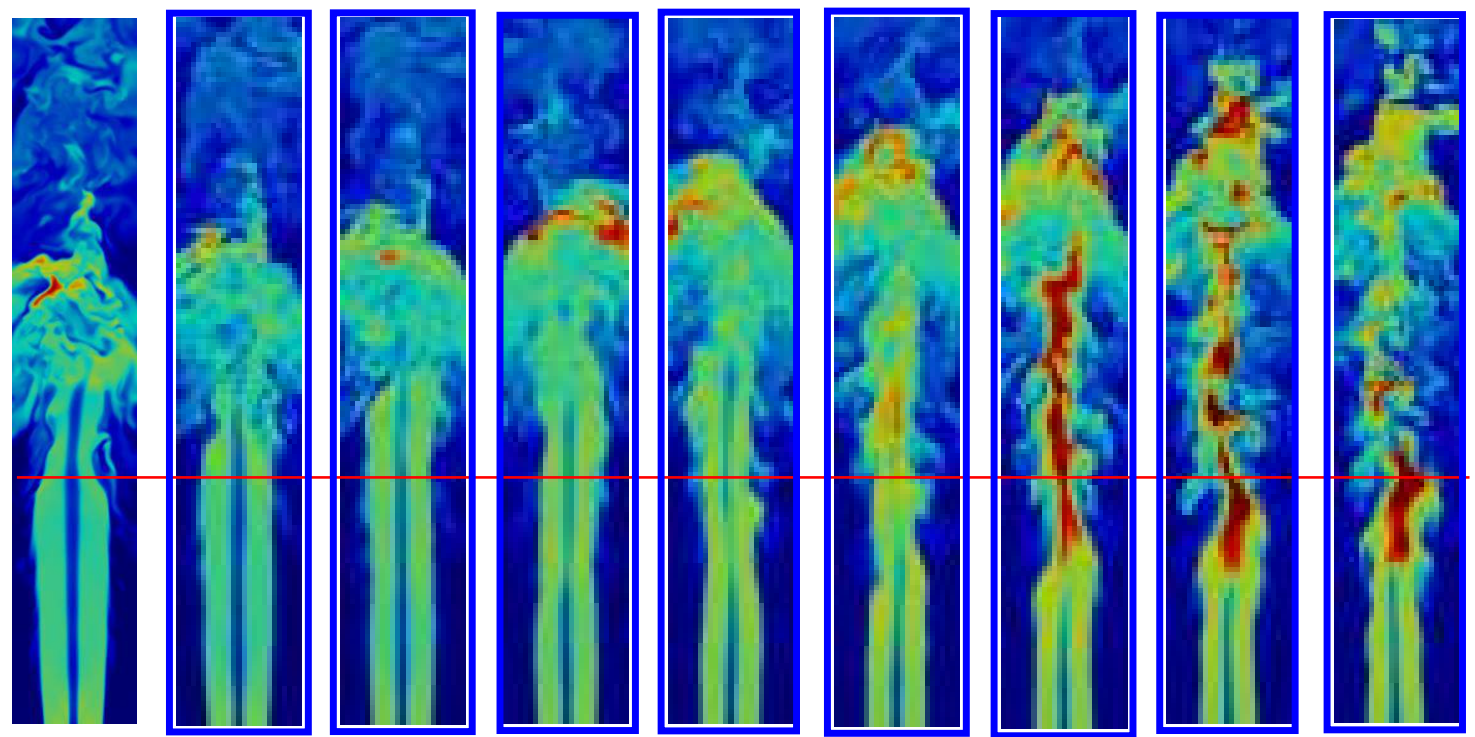

Figure 13. Instantaneous temperature field of WCEC, at $t=t_{1}+n \Delta t, n=1,2,3, \ldots, \Delta t=2 e-5 \mathrm{~s}$.
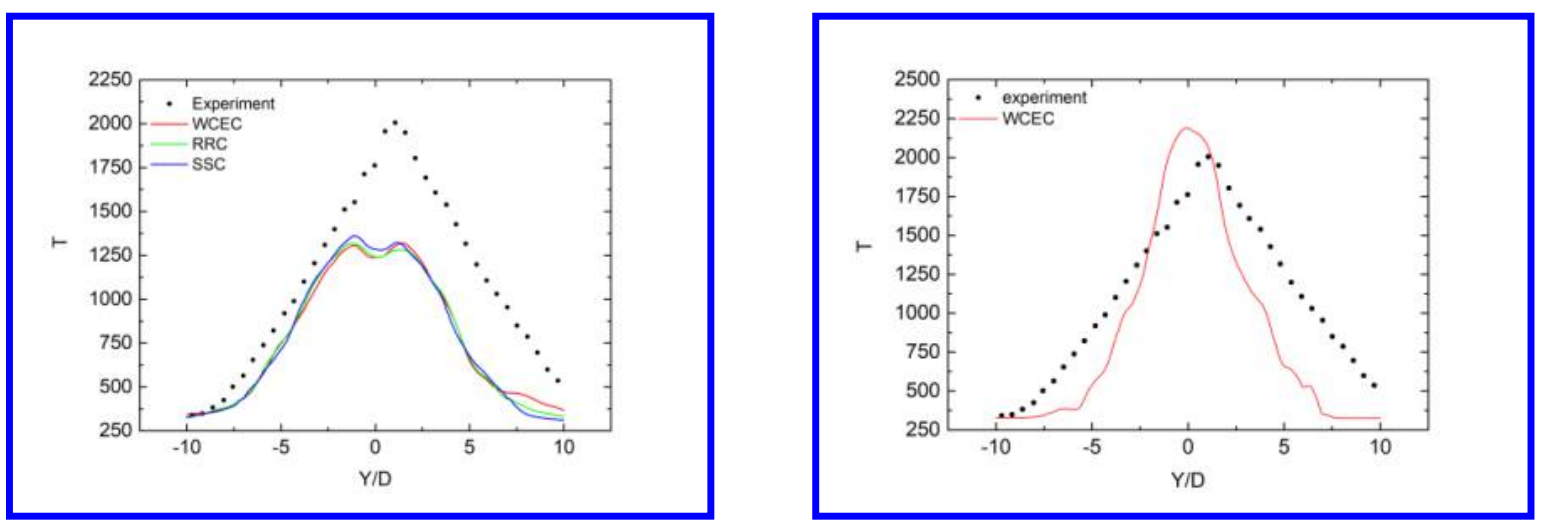

Figure 14. The mean temperature distribution of different averaging time, (a) 3 FTT, (b) 1/3 FTT, at $\mathrm{X} / \mathrm{D}=\mathbf{3 2 . 3}$

Fast Fourier Transfer analysis for the probed temperature fluctuations of the three cases is conducted in figure 15 to reveal the effect of compressibility on periodicity. As see, there is a dominant frequency along with some secondary frequencies. The FTT results of RRC are almost identical with the results of WCEC. However, there are some differences between the WCEC and SSC cased, mainly in the amplitude and the secondary frequencies, implying that the RRC has little effect on the periodicity of the flow fields, whereas SVC has. It seems that the periodicity of combustion fields is mainly controlled by the flow characteristics rather than the chemical reactions.

American Institute of Aeronautics and Astronautics 


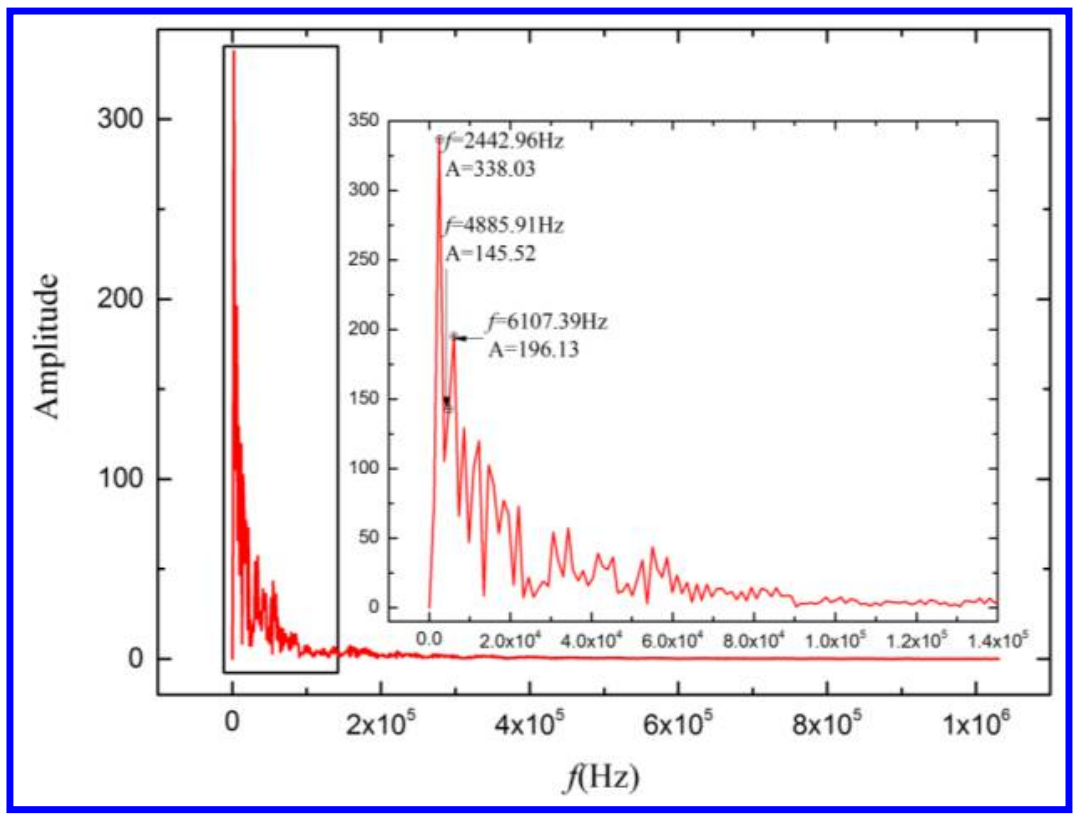

(a)

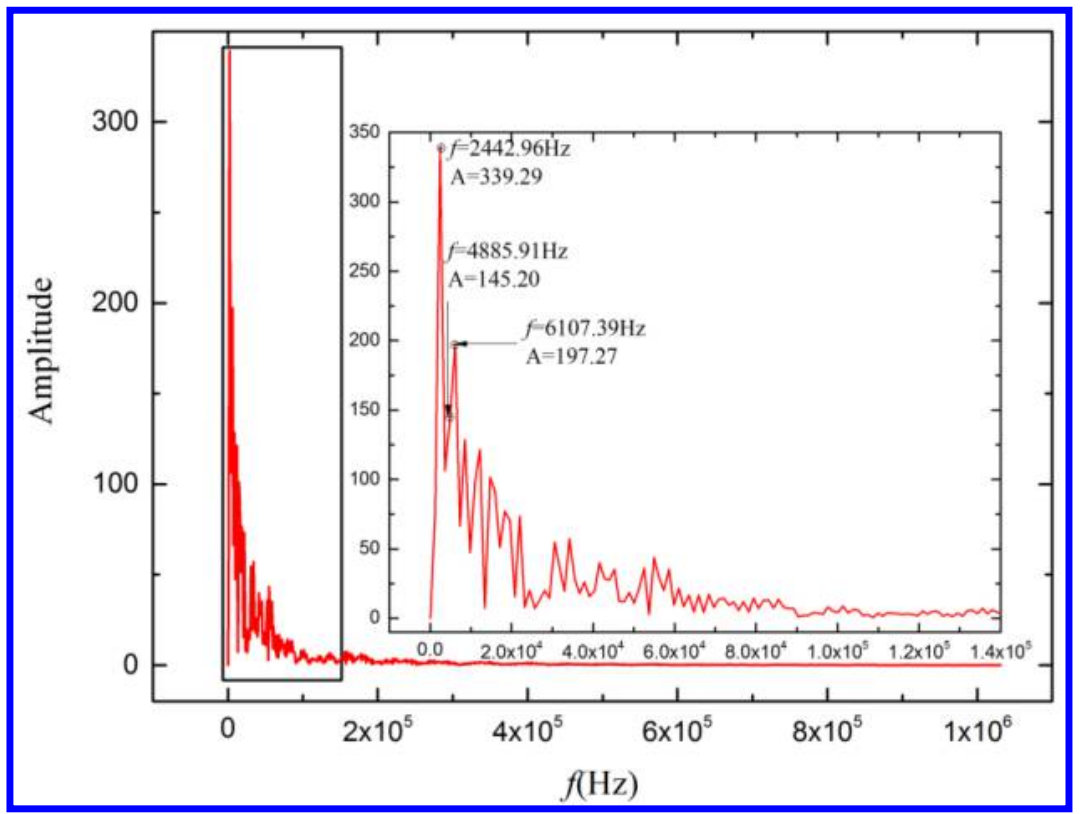

(b) 


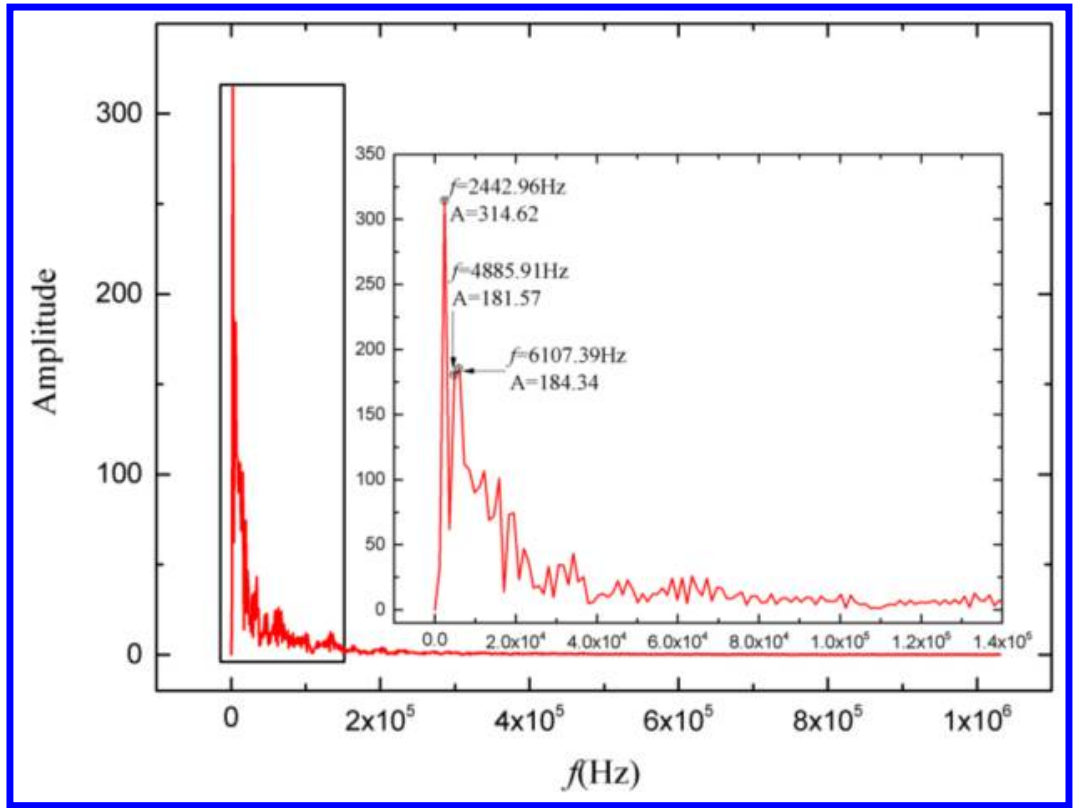

(c)

Figure 15. The Fast Fourier Transform (FFT) of temperature of three cases, a-c) WCEC, RRC, SSC.

\section{E. The Lift-off Heights of Flames}

From Figure 16, the autoignition can occur at a location where the mixing is sufficient and the $\mathrm{HO}_{2}$ is generated. The process of autoignition can be marked by the mass fraction of $\mathrm{HO}_{2}$, therefore the lift-off height is defined as the distance between the location of autoignition and the injector exit. The location of autoignition of three cases is almost the same, therefore, it can be concluded that the compressibility corrections of RRC and SSC have little effect on liftoff height.
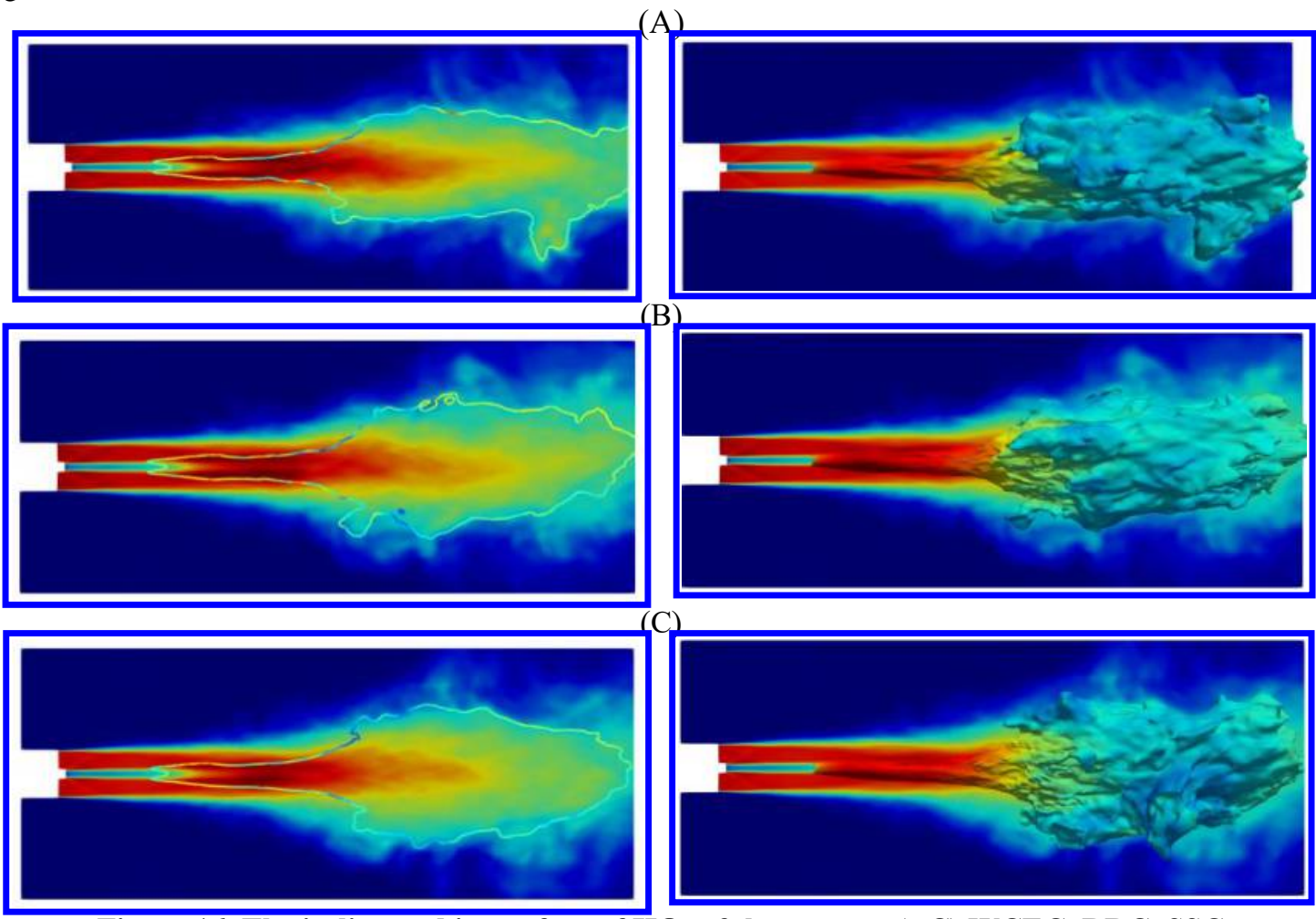

Figure 16. The isoline and isosurface of $\mathrm{HO}_{2}$ of three cases, A-C) WCEC, RRC, SSC

American Institute of Aeronautics and Astronautics 


\section{Conclusions}

In this paper, we concentrate on compressibility effect on supersonic combustion modeling, including reaction rates correction (RRC) and subgrid stress correction (SSC), through comparing with low-Mach LES supersonic combustion modeling (WCEC). This work is carried out from four accepts, including velocity field, composition field, temperature field and lift-off height of the flame. The following conclusions can be drawn:

(1) The compressibility effect on time-averaged velocity field can be ignored, but the instantaneous velocity fields are different between WCEC case and SSC case, because SSC model can accelerate the transition to turbulence.

(2) The two compressibility correction models have an effect on the peak value in the centric position of timeaveraged composition field, and SSC model can promote to keep the symmetry.

(3) The large-scale structures of the time-averaged temperature field of three cases are basically in agreement. There is a periodic phenomenon in the instantaneous temperature field. Through FFT of three cases, we indeed can find main frequency in temperature spectrum map. The spectrum of RRC is in good agreement with WCEC, whereas SSC is different with WCEC in amplitude and secondary frequency. It means that the periodic phenomenon of the supersonic coaxial jet flame is mainly controlled by flow characteristic rather than the combustion process, therefore, the spectrum map of SSC is a little different with WCEC and RRC, because SSC has influenced flow characteristic, through affecting subgrid stress.

(4) Flame lift-off height is marked by the mole concentration of $\mathrm{HO}_{2}$, and the lift-off heights of three cases are almost consistent with each other. It means that compressibility has few effects on flame lift-off height of the supersonic coaxial jet flame.

\section{Acknowledgments}

The project was supported by the Training Program of the Major Research Plan of the National Natural Science Foundation of China (Grant No. 91641110), the Open founding of National Key Laboratory of Science and Technology on Aero-Engine Aero-Thermodynamics (Grant No. 6142702180307), and LHD Innovative Foundation (Grant No. LHD2018JS01). The authors are also grateful to the National Supercomputer Center in Tianjin for providing the computational resource.

\section{References}

\footnotetext{
1. Fureby, C. "LES for Supersonic Combustion," 18th AIAA/3AF International Space Planes and Hypersonic Systems and Technologies Conference. 2012. doi: 10.2514/6.2012-5979

2. Ingenito, A., and Bruno, C. "Physics and Regimes of Supersonic Combustion," AIAA Journal Vol. 48, No. 3, 2010 , pp. 515-525. doi: $10.2514 / 1.43652$

3. Shan, F., Hou, L., Chen, Z., Chen, J., and Su, B. "Two Compressibility Corrections to Flamelet/Progress Variable Model for Supersonic Combustion," 21st AIAA International Space Planes and Hypersonics Technologies Conference. 2017. doi: 10.2514/6.2017-2163

4. Giordano, D. "On the Influence of Medium Compressibility on Chemical-Reaction Rates - Part I_ Theoretical Considerations.pdf," 36th AIAA Thermophysics Conference. Orlando, Florida, 2003. doi: $10.2514 / 6.2003-4057$

5. Ingenito, A., and Bruno, C. "Mixing and Combustion in Supersonic Reactive Flows," 44th AIAA/ASME/SAE/ASEE Joint Propulsion Conference \& Exhibit. 2008. doi: $10.2514 / 6.2008-4574$

6. A. W. Cook, W. H. C. "Hyperviscosity for Shock-Turbulence Interactions," Journal of Computational Physics, 2004. doi: 10.1016/i.jcp.2004.09.011

7. Golovitchev, V. I., Nordin, N., Jarnicki, R., and Chomiak, J. "3-D Diesel Spray Simulations Using a New Detailed Chemistry Turbulent Combustion Model," International Spring Fuels \& Lubricants Meeting \& Exposition. Paris, France, 2000. doi: $10.4271 / 2000-01-1891$

8. Ingenito, A., and Bruno, C. "Mixing and Combustion in Supersonic Reactive Flows," 44th AIAA/ASME/SAE/ASEE Joint Propulsion Conference \&amp; Exhibit. Hartford, CT, 2008. doi: 10.2514/6.2008-4574

9. Cheng, T., S., Wehrmeyer, J. A., and Pite, R., W. "Raman measurement of mixing and finite-rate chemistry in a supersonic hydrogen-air diffusion flame," Combustion and Flame, 1994, pp. 157-173. doi: $10.1016 / 0010-2180(94) 90087-6$
}

American Institute of Aeronautics and Astronautics 
10. Weller, H. G., Tabor, G., Jasak, H., and Fureby, C. "A Tensorial Approach to CFD Using Object Oriented Techniques," COMPUTERS IN PHYSICS Vol. VOL. 12, NO. 6, 1998.

doi:10.1063/1.168744

11. Kee, R. J., Rupley, F. M., Meeks, E., and Miller, a. J. A. "CHEMKIN-111: A FORTRAN Chemical Kinetics

Package for the Analysis of Gas-phase Chemical and Plasma Kinetics." 1996.

12. Greenshields, C. J., Weller, H. G., Gasparini, L., and Reese, J. M. "Implementation of semi-discrete, non-staggered central schemes in a colocated, polyhedral, finite volume framework, for high-speed viscous flows," International Journal for Numerical Methods in Fluids, 2009, pp. n/a-n/a.

doi: 10.1002/fld.2069

13. Wu, K., Li, X., Yao, W., and Fan, X. "Three-Dimensional Numerical Study of the Acoustic Properties of a Highly Underexpanded Jet," 20th AIAA International Space Planes and Hypersonic Systems and Technologies Conference. 2015.

14. Li, X., Wu, K., Yao, W., and Fan, X. "A comparative study of highly underexpanded nitrogen and hydrogen jets using large eddy simulation," International Journal of Hydrogen Energy Vol. 41, No. 9, 2016, pp. 5151-5161. doi: 10.1016/j.ijhydene.2016.01.120

15. Li, X., Wu, K., Yao, W., and Fan, X. "A Comparative Study of Highly Underexpanded Nitrogen and Hydrogen Jets Using Large Eddy Simulation," 20th AIAA International Space Planes and Hypersonic Systems and Technologies Conference. 2015. doi: $10.2514 / 6.2015-3572$

16. Li, X., Yao, W., and Fan, X. "Large-Eddy Simulation of Time Evolution and Instability of Highly Underexpanded Sonic Jets," AIAA Journal Vol. 54, No. 10, 2016, pp. 3191-3211. doi: $10.2514 / 1 . J 054689$

17. Li, X., Zhou, R., Yao, W., and Fan, X. "Flow characteristic of highly underexpanded jets from various nozzle geometries," Applied Thermal Engineering Vol. 125, 2017, pp. 240-253. doi: 10.1016/j.applthermaleng.2017.07.002

18. Yachao, L., Yao, W., and Fan, X. "A low-dissipation scheme based on OpenFoam designed for large eddy simulation in compressible flow," 21st AIAA International Space Planes and Hypersonics Technologies Conference. 2017.

19. Li, X., Fan, E., Yao, W., and Fan, X. "Numerical investigation of characteristic frequency excited highly underexpanded jets," Aerospace Science and Technology Vol. 63, 2017, pp. 304-316. doi: 10.1016/j.ast.2017.01.005

20. Yao, W., Wang, J., Lu, Y., Li, X., and Fan, X. "Full-scale Detached Eddy Simulation of kerosene fueled scramjet combustor based on skeletal mechanism," 20th AIAA International Space Planes and Hypersonic Systems and Technologies Conference. 2015. doi:10.2514/6.2015-3579

21. Wu, K., Zhang, P., Yao, W., and Fan, X. "Numerical Investigation on Flame Stabilization in DLR Hydrogen Supersonic Combustor with Strut Injection," Combustion Science and Technology Vol. 189, No. 12, 2017, pp. 2154-2179. doi: 10.1080/00102202.2017.1365847

22. Yao, W., Lu, Y., Li, X., Wang, J., and Fan, X. "Detached Eddy Simulation of a high-Ma regenerative-cooled scramjet combustor based on skeletal kerosene mechanism," 52nd AIAA/SAE/ASEE Joint Propulsion Conference. 2016. doi:10.2514/6.2016-4761

23. Yao, W., Yuan, Y., Li, X., Wang, J., Wu, K., and Fan, X. "Comparative Study of Elliptic and Round Scramjet Combustors Fueled by RP-3," Journal of Propulsion and Power Vol. 34, No. 3, 2018, pp. 772-786. doi: 10.2514/1.B36721

24. Wu, K., Yao, W., and Fan, X. "Development and Fidelity Evaluation of a Skeletal Ethylene Mechanism under ScramjetRelevant Conditions," Energy \& Fuels Vol. 31, No. 12, 2017, pp. 14296-14305. doi: 10.1021/acs.energyfuels.7b03033

25. Yao, W., Lu, Y., Wu, K., Wang, J., and Fan, X. "Modeling Analysis of an Actively Cooled Scramjet Combustor Under Different Kerosene/Air Ratios," Journal of Propulsion and Power Vol. 34, No. 4, 2018, pp. 975-991. doi: $10.2514 / 1 . B 36866$

American Institute of Aeronautics and Astronautics 